Equilibrium Credit: The Reference Point for Macroprudential Supervisors

Daniel Buncic, Martin Melecky

February 2014 Discussion Paper no. 2013-01 
Editor:

Publisher:

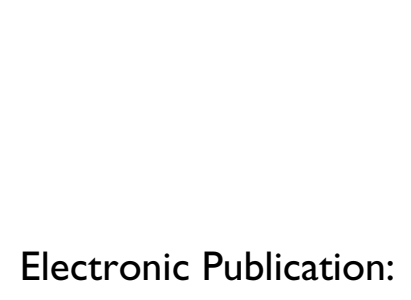

Martina Flockerzi

University of St. Gallen

School of Economics and Political Science

Department of Economics

Bodanstrasse 8

$\mathrm{CH}-9000$ St. Gallen

Phone +41712242325

Fax +41712243135

Email_seps@unisg.ch

School of Economics and Political Science

Department of Economics

University of St. Gallen

Bodanstrasse 8

$\mathrm{CH}-9000$ St. Gallen

Phone $\quad+41712242325$

Fax +41712243135

http://www.seps.unisg.ch 


\section{Equilibrium Credit: The Reference Point \\ for Macroprudential Supervisors ${ }^{1}$}

Daniel Buncic, Martin Melecky

Author's address:

Daniel Buncic

Institute of Mathematics and Statistics

Bodanstrasse 6

$\mathrm{CH}-9000$ St. Gallen

Phone +41712604

Fax $\quad+41712894$

Email daniel.buncic@unisg.ch

Website www.danielbuncic.com

Martin Melecky

Financial \& Private Sector Development

The World Bank

Washington DC

Mail stop H4-410

Phone +12024731924

Email mmelecky@worldbank.org

\footnotetext{
${ }^{1}$ We thank Miguel Dijkman, Joaquin Gutierrez and Maria Soledad Martinez Peria for comments on an earlier draft of this paper. The views and opinions expressed in the paper are those of the authors and do not reflect those of the World Bank or its Executive Directors.
} 


\begin{abstract}
Equilibrium credit is an important concept as it helps identify excessive credit provision. This paper proposes a two-stage approach to determine equilibrium credit. The two stages allow us to study changes in the demand for credit due to varying levels of economic, financial and institutional development of a country. Using a panel of high- and middle-income countries over the period 1980-2010, we provide empirical evidence that the credit-to-GDP ratio is inappropriate to measure equilibrium credit. The reason for this is that such an approach ignores heterogeneity in the parameters that determine equilibrium credit across countries due to different stages of economic development. The main drivers of this heterogeneity are financial depth, access to financial services, use of capital markets, efficiency and funding of domestic banks, central bank independence, the degree of supervisory integration, and experience of a financial crisis. Also, countries in Europe and Central Asia show a slower adjustment of credit to its long-run equilibrium compared to other regions of the world.
\end{abstract}

\title{
Keywords
}

Equilibrium Credit, Macroprudential Supervision, Demand for Credit, Time-Series Panel Data, High- and Middle Income Countries.

\section{JEL Classification}

G28, E58, G21. 


\section{Table of Contents}

1 Introduction $\quad 3$

2 Economic motivation and outline of the proposed framework 6

3 Econometric methodology and data $\quad 9$

3.1 Notion of equilibrium and econometric approach . . . . . . . . . . . . . . . 9

3.1 First-stage ARDL panel regression . . . . . . . . . . . . . . . 10

3.1 .2 Second-stage cross-country regression . . . . . . . . . . . . . 11

3.1.3 Constructing the structural equilibrium credit reference point . . . . . . 12

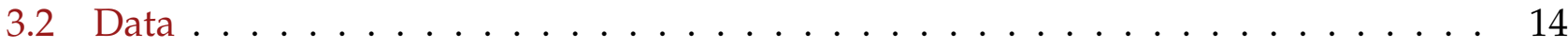

3.2.1 Data sources . . . . . . . . . . . . . . . . . 14

3.2.2 Stylised facts of the data ..................... 16

4 Empirical results $\quad 19$

4.1 Visual overview of the cross-country long-run coefficients . . . . . . . . . . . . . 19

4.2 Mean Group (MG) and Pooled Mean Group (PMG) estimation results . . . . . . . 20

4.2 .1 Mean Group estimates . . . . . . . . . . . . . . . . . . . . 20

4.2.2 Pooled Mean Group Estimates . . . . . . . . . . . . . . . . . . . . . . 21

4.3 Linking the cross-country variation in the income and price elasticities to countryspecific development indicators . . . . . . . . . . . . . . . . . . . . 23

4.3.1 Selecting the subset regressors . . . . . . . . . . . . . . . . 24

4.3.2 Shrinking the subset regressors . . . . . . . . . . . . . . . . 25

4.3.3 Results of the cross-country regression models . . . . . . . . . . . . . . 25

4.4 Discussion of the cross-country regression results . . . . . . . . . . . . . . . . . . . . . . . . . .

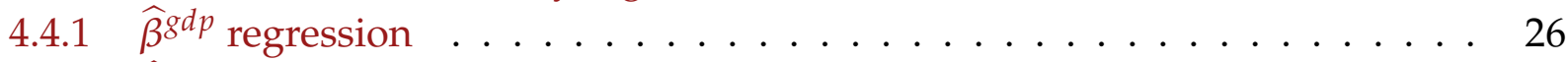

$4.4 .2 \widehat{\beta}^{\text {def }}$ regression . . . . . . . . . . . . . . . . . . 27

4.5 A comparison of equilibrium credit across NMS11 countries . . . . . . . . . 28

5 Conclusion $\quad 35$

$\begin{array}{ll}\text { References } & 36\end{array}$

$\begin{array}{lr}\text { Figures and Tables } & 40\end{array}$

$\begin{array}{lr}\text { Appendix } & 48\end{array}$

A Cross-country distribution of the remaining long-run equilibrium parameters . . 48

B BMA and Lasso results for GDP Deflator . . . . . . . . . . . . . . . . . . . . . 49

C Additional cross-sectional model fit results . . . . . . . . . . . . . . . . . 52

D Robustness check of cross-sectional regression . . . . . . . . . . . . . 53 


\section{Introduction}

Excessive credit provision by the financial system was one of the main sources of the 2008 global financial crisis. ${ }^{1}$ When credit provision becomes excessive is judged against an unobserved benchmark known as equilibrium credit. One of the most challenging aspects of determining excessive credit provision is the estimation of equilibrium credit.

The Basel III regulatory framework proposed by the Basel Committee on Banking Supervision (BCBS) instructs macroprudential supervisors to estimate equilibrium credit by applying the Hodrick-Prescott (HP) filter to the ratio of nominal credit to nominal GDP (henceforth, credit-to-GDP ratio). ${ }^{2}$ Any "significant" deviation of the credit-to-GDP ratio from its HP filtered trend then triggers the accumulation of the counter-cyclical capital buffer. ${ }^{3}$ Although such an approach could be seen as simple and transparent, its purely statistical nature disregards fundamental changes in equilibrium credit due to economic and financial development. There exists substantial evidence that greater financial deepening and broader credit provision can improve access to finance and lead to faster economic growth (Dell'Ariccia et al., 2012, page 5). Excessively restrictive credit, on the other hand, especially in developing economies with increasing credit needs, is likely to result in underinvestment and slow economic growth. Therefore, a structural approach based on economic fundamentals, which accounts for the level of financial development of an economy, seems to be a more appropriate approach to determine equilibrium credit. ${ }^{4}$

The existing literature has studied equilibrium credit provision by estimating long-run credit demand functions. Typically, the focus has been on modelling credit demand using two different dependent variables. For example, Cottarelli et al. (2005), Kiss and Vadas (2007) and Coudert and Pouvelle (2010) use the credit-to-GDP ratio, while Calza et al. (2001), Hofmann (2004), Calza et al. (2003), Brzoza-Brzezina (2005), Coudert and Pouvelle (2010) and Eller et al. (2010), use the ratio of nominal credit to GDP Deflator (henceforth, real credit).

Defining the dependent variable in a credit demand model to be either the credit-to-GDP ratio or real credit imposes strong a priori restrictions on the statistical model that is used, which may not be supported by the empirical data and observed economic behavior. Namely, such restrictions implicitly assume a unit elastic relationship between credit demand and GDP and the GDP Deflator, so that a one-percent increase in GDP or the GDP Deflator is assumed to result in a corresponding one-percent increase in the demand for credit. Although the unit

\footnotetext{
${ }^{1}$ See, for example, Dell'Ariccia et al. (2012). For an earlier account of the relationship between excessive credit growth and financial crises in general, see Loayza and Ranciere (2006).

${ }^{2}$ See page 13 of BCBS (2010).

${ }^{3}$ See Step 3 on pages 13 - 14 in BCBS (2010) on how exactly deviations from equilibrium are tied to increases in the capital buffer, risk weighted assets and what the term "significant" means in relation to percentage points away from the HP filtered trend. How macroeconomic factors can be incorporated in the risk weighting of assets over different phases of the business cycle is described in Buncic and Melecky (2013).

${ }^{4}$ Note here that we are using the term equilibrium in the context of a reference point rather than an outcome of interactions between utility or profit maximizing agents in a micro-founded general equilibrium model.
} 
elasticity assumption might be reasonable for some economies, for many others, particulary developing countries, it will be violated because of the varying usage of credit in economic transactions due to different levels of development. ${ }^{5}$

Cottarelli et al. (2005) and Égert et al. (2006) also consider the effects of changes in development and structural indicators on equilibrium credit demand. They do so by inserting low frequency development and structural indicators into the credit demand equation (the conditional mean equation of credit), together with higher frequency variables that determine credit demand over the business cycle. This approach, however, does not allow for the possibility that the sensitivity of credit to GDP in more credit intensive economies is likely to be higher than in less credit intensive ones. Moreover, especially in time-series panels that include a limited number of countries as in Cottarelli et al. (2005), the development and structural indicators, which change only at a very low frequency, fail to identify any material effects of the indicators on equilibrium credit. Further, mixing higher frequency variables such as GDP, prices and interest rates measured on a quarterly basis with low frequency indicators like financial liberalization or public governance, which typically change over periods much longer than a business cycle, is likely to result in statistical collinearity between the long-term and short-term indicators when both are measured at quarterly frequency. This collinearity makes it difficult to identify the true effects of the long-term indicators on equilibrium credit and derive any reliable policy recommendation.

Other approaches of determining deviations of credit from its long-run equilibrium have been used in the literature. One particular approach uses the Hodrick and Prescott (1997) filter (HP filter) to extract the "smooth" component from the credit-to-GDP ratio. This method is implemented, among others, in Gourinchas et al. (2001), Cottarelli et al. (2005) and is also advocated in the Basel III (2011) regulatory framework. The smooth component is then given the interpretation of the equilibrium level of credit, and any deviations from this HP filtered trend are taken as indications of credit being above or below the financing needs of the economy. An important deficiency of the HP filter based equilibrium credit definition is that it is based on a univariate representation. It provides no information about how credit provision should change in relation to changes in other key economic variables as a country develops. Moreover, the credit-to-GDP ratio is a trending variable. ${ }^{6}$ The HP filter is thus merely used to remove the trend (or permanent) component from the credit-to-GDP ratio to obtain the "stationary" part of the series. We see this as a substantial weakness of the HP filtered credit-to-GDP ratio when used to determine equilibrium credit.

The objective of this study is to propose a structural framework to estimate equilibrium

\footnotetext{
${ }^{5}$ As an example, consider the countries of the US and Croatia. Taking the credit-to-GDP ratio as the dependent variable to model credit demand would imply that the use of credit in economic transactions in these economies is the same. This seems hard to rationalise. One would clearly expect US consumers and businesses to use credit much more frequently in their transactions than consumers and businesses in Croatia.

${ }^{6}$ We summarise some properties of the empirical data later on in Section 3.2.2.
} 
credit which is based on an economy's long-run through-the-cycle transaction demand for credit and which accounts for the effects of economic and financial development on credit demand. The proposed framework consists of three stages. First, we estimate country specific credit demand functions using a quarterly panel data set for high- and middle-income countries from 1980 - 2010. We then model the cross-country variation in the first stage estimates of the income and price elasticities of credit, by regressing the country specific coefficients on a set of "relevant" economic and financial development indicators which we selected with a statistical procedure. In the last step, we use the the second stage fitted (conditional) cross-country averages of the income and price elasticities together with estimates of trend (potential) GDP and GDP Deflator values to compute a structural through-the-cycle estimate of equilibrium credit.

The main advantage of our proposed structural approach is that we are explicitly able to condition on the "average" credit needs of a developing economy that is experiencing structural changes in its intensity of use of credit in economic transaction. We achieve this by using a cross-country approach to compute mean group estimates of the income and price elasticities of credit conditional on a country's level of economic and financial development. Moreover, using the trend components of GDP and the GDP Deflator has the additional benefit that the through-the-cycle potential income generating capacity and trend prices in an economy are used as conditioning variables, rather than current income and prices. This means that for a given set of available income and price elasticities, the level of sustainable credit growth is judged relative to the ability of an economy to maintain those income and price levels over the medium to long-run. As we show in the empirical illustration in Section 4.5, failing to condition upon trend (potential) GDP and GDP Deflator values can lead to a procyclical estimate of equilibrium credit, resulting in potentially distortive macroprudential policy that amplifies booms and intensifies recessions.

The contributions of this study can be summarised as follows. First, we show that the assumption of a unity income and price elasticity of credit, as is implicitly imposed when the credit-to-GDP ratio is used as the dependent variable, is strongly rejected by the data. ${ }^{7}$ This result is confirmed not only visually by the bi-modality in the cross-country distribution of the income elasticity of credit, but also statistically by testing the unity and homogeneity restrictions within the MG and PMG estimation frameworks. Second, we relate the cross-country variation in the income and price elasticities of credit to the level of economic and financial development of the countries in our sample, thereby creating a conditional mean estimate of these elasticities. The main development indicators that explain the cross-country variation in the elasticities are: financial depth, access to financial services, use of capital markets, efficiency and funding of domestic banks, central bank independence, the degree of supervisory integra-

\footnotetext{
${ }^{7}$ Note here, that the view that the income elasticity of credit could be greater than unit is not new (see, for instance, Égert et al., 2006). However, there do not seem to exist any studies that try to quantify or test the magnitude of the income and price elasticities of credit at a cross-country level.
} 
tion, and the experience of a financial crisis. Third, we illustrate how to construct a structural equilibrium credit reference point which is based on the average through-the-cycle transaction demand for credit of an economy and which takes advantage of the historical cross-country income and price elasticities in our sample.

The remainder of the paper is organized as follows. Section 2 discusses the economic motivation behind the proposed empirical approach. Section 3 describes the econometric methodology employed in the paper and the data used in the construction of the different variables of interest. Section 4 presents the empirical results and provides a discussion of the economic significance of the cross-country regression results. Here we also show a comparison of equilibrium credit estimates using the current Basel III framework and our proposed structural approach applied to ten new EU member states, including Croatia. Section 5 concludes the study with a summary of results, policy implications and some directions for future research.

\section{Economic motivation and outline of the proposed framework}

In economies with developed financial markets credit can finance real as well as financial transactions in the same way that cash currency does in less financially developed economies. Humphrey et al. (2004) provides recent empirical evidence that the use of credit in financing transactions has increased considerably since the mid 1990s. In the context of traditional money demand models such as, for example, the cash-in-advance model of Lucas and Stokey (1987), this finding implies that the share of credit goods in the economy increases with financial development. There also exist some earlier theories such as Mitchell-Innes's (1914) credit theory of money which postulates that all transactions in an economy can in fact be viewed as creditbased transactions, stressing the important role of credit in a financially developed economy. ${ }^{8}$

A convenient way to think about the concept of equilibrium credit is to form a parallel to the notion of equilibrium money demand. For this purpose, consider the well known Quantity Theory of Money (QTM) relation of Friedman (1956):

$$
M \times V=T \times P
$$

where $M$ is the quantity of money, $V$ is the velocity of money, $T$ is the volume of real transactions in the economy that require monetary payments, and $P$ is the average unit price of a transaction. ${ }^{9}$ Given the increasing importance of credit based transactions in an economy, the

\footnotetext{
${ }^{8}$ The importance of credit in economic transactions is well known. Werner (2011) provides an interesting recent account of the role of banks and credit in an economy (see in particular Sections 2.1 and 2.2 and also references provided therein for earlier accounts of this relationship).

${ }^{9}$ Note here that we take the simple QTM relation as the base model, nonetheless, the same log-linearised longrun relations for money demand can be arrived at by using a standard money-in-the-utility function model (see Section 2 in Pétursson, 2000 for a detailed derivation of the model).
} 
relation in (1) can equivalently be re-stated with credit $(C R)$ replacing money $(M)$, giving

$$
C R \times V=T \times P
$$

where $C R$ is (nominal) total credit to the private sector (simply credit henceforth). ${ }^{10}$

In empirical studies, it is common to approximate the volume of transactions $T$ in the economy by real GDP and the average unit price of a transaction $P$ by the GDP Deflator. ${ }^{11}$ For estimation purposes, it is further standard to log-linearize the relation in (2) and explicitly allow the real income and price elasticities to differ from unity by re-writing the relation in (2) as:

$$
c r_{t}-\underbrace{\left(\beta^{g d p} g d p_{t}+\beta^{d e f} d e f_{t}\right)}_{=\text {nominal GDP }}=v_{t} .
$$

The terms $c r_{t}, g d p_{t}, d e f_{t}$ and $v_{t}$ in (3) are (natural) logarithms of credit, real GDP, the GDP Deflator and credit velocity. ${ }^{12}$ The parameters $\beta^{g d p}$ and $\beta^{\text {def }}$ capture, respectively, the sensitivity (or elasticity) of credit to output and to the price level. The credit velocity term $v_{t}$ in (3) can be driven by a number of different determinants. The most commonly used ones are "own" and "alternative" returns to investment (see Tobin, 1969). ${ }^{13}$

The considered determinants of velocity in this study are: (i) own returns on the cost of credit (the lending rate), (ii) alternative returns on deposits (the deposit rate), and (iii) alternative returns from purchasing goods or services (the inflation rate), all related to local currency transactions. In empirical money demand studies, it is commonly found that the alternative cost of borrowing in foreign currency is an important determinant of money demand in open economies (see Arango and Nadiri, 1981 and Brissimis and Leventakis, 1985, among others). As the majority of countries in our sample are open economies, we also include the cost of borrowing in foreign currency, that is, the foreign interest rate adjusted for changes in the nominal exchange rate, as an alternative return on borrowing in foreign currency.

One practical issue that we encountered when using both domestic lending as well as deposit rates in the specification of credit velocity in (3) was that for a large number of countries these rates are highly correlated. Because of this, we specify the credit velocity equation in terms of spreads, using the local currency lending rate as the basis. The empirical process driv-

\footnotetext{
${ }^{10}$ See also page 30 in Werner, 2011 for essentially the same representation.

${ }^{11}$ It is also possible to use other available price measures such as the CPI or PPI. Nonetheless, since the GDP Deflator is consistent with the calculation of real GDP, we prefer to write the representation in terms of the GDP Deflator. From this point onwards, we will also use the GDP Deflator in the notation of the paper.

${ }^{12}$ Note that it should be $-v_{t}$ on the right-hand side of (3). However, since the sign can be absorbed in the coefficients of the terms in the velocity equation, this has no significance. We therefore do not explicitly write down the negative sign.

${ }^{13}$ We will focus only on the main drivers of credit velocity $v_{t}$, as there potentially exist several explanatory variables that could be used. The main reason for this is practicality and data availability. Our objective is thus to condition on a relatively parsimonious set of velocity determinants that will be available for a large number of countries and over a long enough period in our panel data set.
} 
ing credit velocity thus takes the form:

$$
v_{t}=\beta^{r r} r r_{t}+\beta^{s p r d} s p r d_{t}+\beta^{a c b} a c b_{t}
$$

with the main determinants being the real domestic interest rate $\left(r r_{t}\right)$, the lending-deposit rate spread $\left(\operatorname{spr} d_{t}\right)$, and the alternative cost of borrowing in foreign currency $\left(a c b_{t}\right) \cdot{ }^{14}$ A priori, we expect that increases in $r r_{t}, s p r d_{t}$ and $a c b_{t}$ in (4) should lead to, respectively, a decline in the demand for credit, an increase in saving deposits, and a decline in the demand for credit in foreign currency.

Since the global financial crisis, the credit-to-GDP ratio has become the focal point for macroprudential supervisors when discussing excessive provision of credit to the real economy. ${ }^{15}$ To see how the credit-to-GDP ratio is related to our specification of credit demand, we can combine (3) and (4) to relate the disequilibrium provision of credit to the real economy to credit velocity as:

$$
\underbrace{=\overbrace{c r_{t}-\left(\beta^{g d p} g d p_{t}+\beta^{d e f} d e f_{t}\right)}^{\text {credit-to-GDP ratio if } \beta^{g d p}=\beta^{d e f}=1}}_{\text {excess of transaction demand }}=\underbrace{\overbrace{\beta^{r r} r r_{t}+\beta^{s p r d} s p r d_{t}+\beta^{a c b} a c b_{t}}^{\text {credit velocity equation }}}_{\text {portfolio/speculative demand }} .
$$

The left-hand side of (5) can be viewed as an "unrestricted" version of the credit-to-GDP ratio, explicitly allowing the elasticities of credit to GDP and the price level, as measured by the GDP Deflator, to differ from unity. The right-hand side of (5) is a time-varying measure of disequilibrium credit provision which captures the excess or the lack of credit supplied to the real economy that does not satisfy transaction demand. Equation (5) thus postulates that credit in excess of the transaction demand for credit, as shown on the left-hand side of (5), is provided to satisfy speculative (or portfolio) demand for credit. It is this quantity that affects asset prices by stimulating the formation of asset price bubbles and hence persistent deviations of credit velocity from its long-run steady-state value. Prudential supervisors should therefore focus on managing large departures of credit from its transaction demand component, that is, the left hand side of (5).

The relation in (5) describes a theoretical long-run equilibrium relationship. In order to compute the right-hand side of equation (5), which captures the time-varying disequilibrium credit provision to the real economy, one only needs estimates of $\beta^{g d p}$ and $\beta^{d e f}$ of the lefthand side relation of (5). Nevertheless, as for any statistical estimation problem, one needs to condition on all relevant explanatory variables that influence the dependent variable to obtain consistent estimates of $\beta^{g d p}$ and $\beta^{d e f}$. In our context, this means that we need to condition on the velocity determinants that appear on the right-hand side of equation (5) as well as on GDP and the price level, ie., the $g d p_{t}$ and $d e f_{t}$ variables, that appear on the left-hand side. Moreover, it is important to leave $\beta^{g d p}$ and $\beta^{\text {def }}$ on the left-hand side of (5) unrestricted, since estimates of

\footnotetext{
${ }^{14}$ Details regarding the exact construction of these variables are provided in the Data Section.

${ }^{15}$ See, for example, Basel III (2011) and the technical documentation in BCBS (2010).
} 
all other parameters in the velocity equation will be biased if the imposed restrictions are not supported by the data.

Leaving the $\beta^{g d p}$ and $\beta^{\text {def }}$ parameters in (5) unrestricted is an important generalisation of the credit-to-GDP ratio, as it allows us to view any restrictions that are imposed on the data as a testable implication of the model. In the above context, this means that the unity restriction which is imposed on $\beta^{g d p}$ and $\beta^{d e f}$ when the credit-to-GDP ratio is used to estimate equilibrium credit can be statistically tested for validity. Given that there exists ample evidence in the empirical money demand literature that the typical range of parameter estimates of the income elasticity (of money demand) across countries is between $0.25-3.5$ (Sriram, 2001, page 360), we also anticipate considerable heterogeneity in the $\beta^{g d p}$ and $\beta^{\text {def }}$ estimates across countries in our setting. This heterogeneity will reflect the different levels of access to credit, the capacity of the financial system to intermediate credit, and the intensity of use of credit in economic transactions and therefore will be related to the overall level of economic, financial and institutional development of the country.

Leaving the $\beta^{g d p}$ and $\beta^{d e f}$ elasticities in (5) unrestricted also has the added benefit of allowing us to model the cross-country variation by relating it to a set of "relevant" economic, financial and institutional development indicators. This has the advantage that we will be able to construct cross-country equilibrium estimates of the income and price elasticities which are obtained by explicitly conditioning on a set of key economic variables that account for the level of development of a country. Computing equilibrium estimates of the income and price elasticities in this way allows us to average across the actual historical credit cycles of the economies that we study, controlling for the different levels of economic and financial development. A standard mean group estimate of the coefficients computed as the unconditional cross-sectional average does not control for these differences and would thus result no only in biased estimates of the equilibrium elasticities but also in a biased equilibrium credit reference point.

\section{Econometric methodology and data}

\subsection{Notion of equilibrium and econometric approach}

Several methodological approaches to determine equilibrium credit exist in the literature. The notion of equilibrium credit adopted in this study is in line with the notion of "long-run equilibrium" followed in the economics literature in general, as discussed, among others, in Pesaran (1997). That is, we perceive equilibrium credit to be linked conceptually to the economic notion of the "long run". Note that the notion of the long-run in the recent econometric literature is frequently associated with the literature on co-integration of individually integrated economic time-series. Although the econometric approach that we follow in the first stage of our approach allows for the existence of a co-integrating relationship between individually integrated variables, integration of the individual series is not a prerequisite, as it is still possible to for- 
mulate an equilibrium relationship between a set of stationary variables. Therefore, there is no need to test for the order of integration of the individual series.

\subsubsection{First-stage ARDL panel regression}

Given our notion of equilibrium, we specify the econometric model as an Autoregressive Distributed Lag (ARDL) model. Since our main objective is a cross-country comparison of the long-run parameter estimates in the equilibrium specification, we apply the ARDL model to a cross-country panel data set, using the Mean Group and Pooled Mean Group estimators of Pesaran and Smith (1995) and Pesaran et al. (1999).

The Mean Group (MG) estimator considers individual country time series regressions and constructs an estimator for the entire group by averaging over the coefficients of the individual countries. The Pooled Mean Group (PMG) estimator takes advantage of the possibility that the long-run equilibrium relations across the groups (countries) could be homogenous and restricts all or some of the long-run equilibrium parameters to be the same across the groups. The aggregate short-run dynamics are again arrived at by averaging across the country specific estimates (see also Pesaran et al., 1999, for a general motivation of the Pooled Mean Group estimator).

The empirical ECM form of the ARDL model that we work with is:

$$
\Delta c r_{i t}=k_{i}+\alpha_{i}\left(c r_{i t-1}-\boldsymbol{\beta}_{i}^{\prime} \boldsymbol{x}_{i t-1}\right)+\sum_{p=1}^{P} \pi_{p i} \Delta c r_{i t-p}+\sum_{q=0}^{Q} \gamma_{q i}^{\prime} \Delta \boldsymbol{x}_{i t-q}+\epsilon_{i t}
$$

where $k_{i}$ and $\alpha_{i}$ are country specific intercept and speed of adjustment parameters, $\boldsymbol{\beta}_{i}$ is a $(5 \times 1)$ dimensional parameter vector capturing the country specific long-run equilibrium, ie., $\beta_{i}=\left(\beta_{i}^{g d p}, \beta_{i}^{d e f}, \beta_{i}^{r r}, \beta_{i}^{s p r d}, \beta_{i}^{a c b}\right)^{\prime}$ and the $(5 \times 1)$ vector $\boldsymbol{x}_{i t}$ contains the variables of interest for country $i$ at time $t$, where $x_{i t}=\left(g d p_{i t}, d e f_{i t}, r r_{i t}, s p r d_{i t}, a c b_{i t}\right)^{\prime}$. The parameters $\pi_{p i}$ and $\gamma_{q i}$ allow for extra dynamics in the dependent variable $\Delta c r_{i t}$ up to lag order $P$ and up to $Q$ extra lags in the vector of explanatory variables, respectively.

Specifications similar to the one given in (6) have been used in previous studies (see, for example, Cottarelli et al., 2005 and Égert et al., 2006). However, what distinguishes our study from earlier ones is that we do not a priori restrict the parameters attached to GDP and the GDP Deflator to unity. Our view is that using the credit-to-GDP ratio as the dependent variable is overly restrictive and that it is a testable implication of the model on the data that needs to be verified empirically. The approach that we follow leaves the effect of GDP and the GDP Deflator on credit unrestricted. This enables us to determine how appropriate the unity restrictions are at the aggregate level. More importantly, it further allows us to look at the cross-country variation in the $\hat{\beta}_{i}^{g d p}$ and $\hat{\beta}_{i}^{d e f}$ coefficients to see if there are any fundamental differences in their magnitudes. We can then use statistical tests to determine whether the homogeneity assump- 
tion and the unity restrictions on the $\beta_{i}^{g d p}$ and $\beta_{i}^{d e f}$ parameters across countries are supported by the data. It is well known that imposing invalid restrictions on a subset of parameters leads to substantial distortions in the estimates of all remaining unrestricted parameters.

\subsubsection{Second-stage cross-country regression}

Since we are particularly interested in the cross-country variation of the long-run coefficients on real GDP and the GDP Deflator in (6), we proceed by relating the variation in the first stage estimates $\hat{\beta}_{i}^{g d p}$ and $\hat{\beta}_{i}^{\text {def }}$ to a set of development indicators. These indicators are obtained from a number of different sources, such as the FinStats database of Al-Hussainy et al. (2011) and the Financial Structure data set of Beck et al. (2000). We also add various economic development indicators to these two databases. As no well developed economic theory exists to provide guidance in the selection of the relevant regressors for $\hat{\beta}_{i}^{g d p}$ and $\hat{\beta}_{i}^{d e f}$, we further add traditional scale variables such as the level of economic development (i.e., GDP per capita) to control for an economy's size, and the degree of openness. Lastly, we include a data set on financial sector supervisory structures from Melecky and Podpiera (2012). This last set contains measures of the degree of integration in prudential supervision, the pursuit and integration of business conduct supervision, and central bank independence. The Kaufmann et al. (2010) governance indicators are also included. ${ }^{16}$ All together, a total of 42 economic, financial and institutional development indicators are available.

Our objective is to relate the cross-country variation in $\hat{\beta}_{i}^{g d p}$ and $\hat{\beta}_{i}^{\text {def }}$ to the most relevant development indicators of an economy. Once the variation in these coefficients is linked to these development indicators, it will be possible to determine equilibrium credit provision for a specific country conditional on its development stage, its financing needs, and the capacity of its financial sector to meet these needs. Our proposed framework therefore measures current credit provision in the economy relative to what is needed to maintain a financially stable economic growth path over the medium to long-run.

The relationship between the coefficients and the considered development indicators is estimated using a second stage regression model taking the form:

$$
\hat{\beta}_{i}^{m}=\phi_{0}^{m}+\sum_{\ell=1}^{L} \phi_{\ell}^{m} z_{\ell i}+\varepsilon_{i}^{m}, \forall m=\{g d p, \operatorname{def}\},
$$

where $\hat{\beta}_{i}^{g d p}$ and $\hat{\beta}_{i}^{d e f}$ are the coefficients on real GDP and the GDP Deflator estimated from the relation in (6), $\left\{\phi_{j}^{g d p}\right\}_{j=0}^{L}$ and $\left\{\phi_{j}^{d e f}\right\}_{j=0}^{L}$ are the corresponding second stage regression parameters that capture the cross-country variation, and $\varepsilon_{i}^{g d p}$ and $\varepsilon_{i}^{d e f}$ are disturbance terms with zero mean and constant variance. The regressors $\left\{z_{\ell i}\right\}_{\ell=1}^{L}$ are relevant economic and financial development indicators that need to be selected from the larger set listed above.

\footnotetext{
${ }^{16} \mathrm{~A}$ description of the explanatory variables that we use is provided in the Data Section.
} 
After the model in (7) has been fitted, estimates of $\left\{\phi_{j}^{g d p}\right\}_{j=0}^{L}$ and $\left\{\phi_{j}^{d e f}\right\}_{j=0}^{L}$ will be available, which can then be used to compute the second stage fitted (or projected) values. ${ }^{17}$ We will denote these fitted values by $\bar{\beta}_{i}^{g d p}$ and $\bar{\beta}_{i}^{\text {def }}$. A convenient way to think about the second stage fitted values $\bar{\beta}_{i}^{g d p}$ and $\bar{\beta}_{i}^{\text {def }}$ is to view them as conditional analogues of the unconditional means obtained from the MG estimator. To see this relationship, suppose that none of the regressors $\left\{z_{\ell i}\right\}_{\ell=1}^{L}$ have any explanatory power for the two (dependent) variables $\hat{\beta}_{i}^{g d p}$ and $\hat{\beta}_{i}^{d e f}$, so that all $\left\{\hat{\phi}_{\ell}^{m}\right\}_{j=1}^{L}$ coefficients are in fact equal to zero. Then, the best fitting model is just a model with a constant term in the regression. But this simply returns the unconditional (cross-sectional) mean of $\hat{\beta}_{i}^{g d p}$ and $\hat{\beta}_{i}^{d e f}$ and is hence by definition the MG estimator. The second stage regression step in (7) can therefore be viewed as a generalisation of the MG estimator, a conditional MG estimator.

Computing conditional rather than unconditional cross-country averages is important in our proposed structural framework, because it allows us to control for the level of economic and financial development of the different countries in our data set when computing the equilibrium income and price elasticities. Credit cycles are known to be between three to four times longer than business cycles and have a median duration of about 15 years (see Drehmann et al., 2010, page 28). To get "robust" estimates of the income and price elasticities that are not specific to a single credit cycle, one will need to average over various different credit cycles. This can be done in two different ways. One can consider a very long time series for a single economy that has experienced a number of credit cycles. Or, one can look at the cross-section of credit cycles and average over the different country experiences. To do the former, a very long time series needs to be available. ${ }^{18}$ For the latter approach, it is necessary to condition on different levels of development. Our view is that conditionally averaging over the cross-section provides a richer framework, as it has a broader empirical representation of the actual historical credit cycles of the economies that we study.

\subsubsection{Constructing the structural equilibrium credit reference point}

Once fitted values $\bar{\beta}_{i}^{g d p}$ and $\bar{\beta}_{i}^{\text {def }}$ from the regression in (7) are available, it is possible to construct the equilibrium credit reference point from the transaction demand relation on the left hand side of equation (5). That is, for country $i$ one could compute equilibrium credit at time $t$ as:

$$
\tilde{c r}_{i t}^{e q}=\bar{\beta}_{i}^{g d p} g d p_{i t}+\bar{\beta}_{i}^{d e f} d e f_{i t}
$$

\footnotetext{
${ }^{17}$ These are computed in the standard way as $\bar{\beta}_{i}^{m}=\hat{\phi}_{0}^{m}+\sum_{\ell=1}^{L} \hat{\phi}_{\ell}^{m} z_{\ell i}$, where $\left\{\hat{\phi}_{j}^{m}\right\}_{j=0}^{L}$ are OLS estimates of the parameters in (7).

${ }^{18}$ It will also be necessary to control for the (slow) evolution of economic, financial and institutional development in that single economy. This means that we will need to have repeated readings of the control indicators that we use at say $10-15$ year frequencies. This may not be feasible due to the lack of data availability. The bulk of data that is related to economic and financial development seems to have accrued only over the last $20-30$ years. This would mean that one would only have, at best, up to $2-3$ different updating periods for the slowly moving development indicators.
} 
where $g d p_{i t}$ and $d e f_{i t}$ are the actual (level) series of GDP and the GDP Deflator of the individual countries. ${ }^{19}$ One issue with using actual (level) values to compute equilibrium credit is that it does not consider trend or potential of GDP and the GDP Deflator. In the terminology of Basel III, the relation in (8) is thus using point-in-time (PIT) values for output and the price level, rather than through-the-cycle (TTC) ones.

Recall that $\bar{\beta}_{i}^{g d p}$ and $\bar{\beta}_{i}^{\text {def }}$ are not only averaged across different countries, but also across different business cycles. This is inline with a through-the-cycle (TTC) view of the elasticities. To construct a measure of equilibrium credit that is consistent with the TTC view of Basel III, we therefore use trend estimates of GDP and the GDP Deflator as the conditioning variables in the transaction demand equation in (5). Our preferred TTC estimate of equilibrium credit is hence computed as:

$$
\overline{c r}_{i t}^{e q}=\underbrace{\bar{\beta}_{i}^{g d p} \overline{g d p}_{i t}+\bar{\beta}_{i}^{d e f} \overline{d e f}_{i t}}_{\begin{array}{c}
\text { TTC equilibrium credit demand based on } \\
\text { conditional cross-country averages } \\
\text { at potential GDP and DEF }
\end{array}}
$$

where $\overline{g d p}_{i t}$ and $\overline{d e f}_{i t}$ are estimates of trend (or potential) GDP and the GDP Deflator. Deviations from this equilibrium credit reference point can then simply be computed as the difference between credit and equilibrium credit, that is, $c r_{i t}-\overline{c r}{ }_{i t}^{e q}$. We will refer to this quantity as the "credit gap" from now on.

To provide some extra intuition as to why trend values of GDP and the GDP Deflator should be used instead of level values, consider the following simple example. Suppose that an economy is experiencing an economic expansion so that GDP grows at $5 \%$ (per annum), which is above its long term inflation stable growth path of $2.5 \%$. Suppose further that $\bar{\beta}^{\text {gdp }}=2$ and, for simplicity, that $\bar{\beta}^{\text {def }}$ def $=0$, to focus on the effect of GDP only. If GDP stood at 100 last period and the economy has grown $5 \%$, then using the relation in (8), equilibrium credit is estimated to be: $\widetilde{c r}^{e q}=\bar{\beta}^{g d p} g d p+\bar{\beta}^{d e f} d e f=2 \times 105=210$. It is easily seen that this estimate of equilibrium credit is above the one computed from (9), which is $\overline{c r} e q=2 \times 102.5=205$, when conditioning on trend GDP. Thus, in an expansion phase of the business cycle, equilibrium credit is estimated to be higher due to GDP being above potential (or trend), leading to an overestimate of the trough-the-cycle transaction demand for credit. Similarly, during a down turn, when the economy grows below potential, the opposite will occur and credit will be restricted too harshly. Not using potential GDP (and GDP Deflator) values in the computation of equilibrium credit has the consequence of creating a procyclical measure, potentially resulting in distortive macroprudential policy that amplifies booms and intensifies recessions.

Estimates of trend (or potential) GDP and the GDP Deflator can be computed in a number of

\footnotetext{
${ }^{19}$ Clearly, one could also compute equilibrium credit as $\widehat{c}{ }_{i t}^{e q}=\hat{\beta}_{i}^{g d p} g d p_{i t}+\hat{\beta}_{i}^{d e f} d e f_{i t}$, where $\hat{\beta}_{i}^{\text {gdp }}$ and $\hat{\beta}_{i}^{d e f}$ are the country specific income and price elasticities computed from the individual time series regressions. However, this estimate of equilibrium credit would be country as well as credit cycle specific, and would not take advantage of the historical cross-country information in the data. It would also not conform to the TTC view of equilibrium credit. Therefore, we believe that it is not a suitable benchmark to be used in policy discussion.
} 
different ways. For instance, an easy to implement non-parametric way of obtaining potential estimates would be to apply the HP filter to the GDP and GDP Deflator series and then use the extracted trend component of the series. If a more parametric estimate is preferred, one could fit low order ARMA models to GDP growth and inflation and then construct the trend component using the Beveridge and Nelson (1981) decomposition. For some countries, the national statistical authority or the central bank provide estimates of potential GDP (see the GDPPOT series in the FRED database for the US). Estimates of the potential price level (GDP Deflator) could alternatively also be constructed from inflation targets published by the national central bank. As a third alternative way, the inflation targets together with estimates of potential output could be used to construct estimates of potential GDP and the GDP Deflator to compute equilibrium credit from the relation in (9). ${ }^{20}$

One major advantage of our proposed framework, especially for policy related work, is that the computation of (9) does not require any historical data on credit, GDP or the GDP Deflator. As long as the selected subset of relevant development indicators that are used in the crosscountry regressions are available (see Table 5 for this list), projected values of the income $\left(\bar{\beta}_{i}^{\text {gdp }}\right)$ and price elasticities $\left(\bar{\beta}_{i}^{\text {def }}\right)$ of credit can be constructed. ${ }^{21}$ If no historical data are available or are viewed to be unreliable, long term country level forecasts of GDP growth and inflation from international institutions such as the Economic Intelligence Unit, the International Monetary Fund or the World Bank can be used to construct estimates of potential GDP and the GDP Deflator. ${ }^{22}$

\subsection{Data}

\subsubsection{Data sources}

The source of our data set is the IMF's International Financial Statistics (IFS) database. All data is on a quarterly basis. The maximum possible sample size in the time dimension is from 1980:Q1 to 2010:Q3. The cross sectional dimension of the panel data set, i.e., the number of countries that are included, is $N=49 .^{23}$ The credit variable that we use is defined as total bank credit to the private sector, expressed in local (national) currency units. ${ }^{24}$ Since the scale of

\footnotetext{
${ }^{20}$ We provide an empirical example of our proposed structural approach in Section 4.5.

${ }^{21}$ Note that there are over 180 countries in the Finstats database, so the coverage in terms of countries is rather broad.

${ }^{22}$ One well known problem with using macroeconomic data for real time macroprudential policy is that GDP and the GDP Deflator are released with a fairly long time delay and are subject to revisions (see Croushore and Stark (2001) for release lags and revision examples for the US). Policy makers often need to have a reliable measure of equilibrium credit before these figures become available for a timely policy response to be implemented. Using projected values from the above listed databases can substantially improve real time policy implementation, as equilibrium credit can be constructed for future values based upon forecasts of potential output and the price level.

${ }^{23}$ We do not provide a separate table that lists the countries included in the panel data set to conserve space, nonetheless, the $x$-axis labels of Figure C.2 in the Appendix show explicitly which countries are included.

${ }^{24}$ This is entry d22 in the IMF's IFS database, which is: "claims on the private sector by commercial banks and other financial institutions". This series includes credit provided by domestically owned banks and foreign owned banks.
} 
private sector credit can be very different across the countries, we create a credit index, where the base of the index (index value is 100) is 2001:Q1. The index version of the credit variable is then log transformed before used in the analysis.

The real GDP data (GDP for short henceforth) and GDP Deflator data are taken from volume measures, and are hence also index measures with different base years. Both, GDP and the GDP Deflator are also log transformed. The lending to deposit rate spread is computed as the lending rate minus the deposit rate. We use Consumer Price Inflation (CPI) data to construct an ex-post measure of the real interest rate. This is done by computing CPI inflation as 100 times the year-on-year inflation rate, ie., as $100 \times\left(\ln \left(C P I_{i t}\right)-\ln \left(C P I_{i t-4}\right)\right){ }^{25}$ The real interest rate is then calculated as the lending rate minus year-on-year inflation. The alternative cost of borrowing variable, which captures the cost of borrowing in foreign currency, is calculated as the country specific lending rate minus the world interest rate minus the year-on-year change in the exchange rate. The exchange rate is defined as the number of local currency units per one US dollar, so that a declining value indicates an appreciation of the respective country's currency against the US dollar. To avoid unnecessary volatility in the exchange rate series, we use quarterly averages rather than end-of-quarter values. For the US, we use (the inverse) of the Trade Weighted Exchange Index of major currencies to get a measure of the exchange rate impact on credit. ${ }^{26}$ The world lending rate is approximated by the US dollar lending rate.

A few additional comments on the data set that we use and the data transformations that we apply are in order. The set of countries consists of a reasonable mix of developed and emerging market economies with a satisfactory north/south and continental representation. The initial cross-sectional dimension consisted of 65 countries, but due to the lack of largely GDP and GDP Deflator data as well as lending and deposit rates, it was necessary to exclude countries that did not have data available for a long enough period.

There were further occasional data gaps that were interpolated with a linear interpolation method to keep the size of the sample as large as possible. These were occasional gaps in the lending and deposit rates of some countries, and very rarely also in the credit series. For EU countries, we have converted the relevant variables and the exchange rate to euro-denominated values prior to the $1^{\text {st }}$ of January 1999 , where the official EU conversion rates were used. ${ }^{27}$ Also, although the real GDP data were marked as seasonally adjusted, it became evident from visual inspection of the series that for a handful of countries that were included in the final data set, this was in fact not the case. It was, therefore, necessary to use a seasonal filter to remove the seasonality in those GDP series. For this, the X12-ARIMA seasonal filter of the US Census

\footnotetext{
${ }^{25}$ We use year-on-year values, rather than annualised quarter-on-quarter values, to reduce the volatility of the inflation series.

${ }^{26}$ This series was obtained from the FRED2 database of the Federal Reserve Bank of St. Louise. The series code is DTWEXM and was aggregated to quarterly averages. We use the inverse to be consistent with the definition of a decreasing value implying an appreciation of the domestic currency for non-US countries in the cross-section.

${ }^{27}$ See http:/ / ec.europa.eu/economy_finance/euro/adoption/conversion/index_en.htm.
} 


\section{Bureau was used..$^{28}$}

The number of time-series observations of each of the 49 countries that are included in the cross-section ranges from 25 observations for Bulgaria up to 118 observations for France. Evidently, having less than 40 observations for the time-series dimension is far from optimal, nonetheless, we chose to leave as many cross-sections in the final data set as possible. A brief summary of the number of time-series observations of the individual countries is as follows: there are only 5 countries with less than 40 observations, there are 21 countries with 100 observations or more and the remaining countries have between 40 and 92 time-series observations.

The regressor variables intended to capture the cross sectional variation in the GDP and GDP Deflator coefficients were taken from the FinStats and Financial Sector Development Indicators of Al-Hussainy et al. (2011) and Beck et al. (2000). The economic development indicators are GDP per capita as a measure of economic development, the foreign trade to GDP ratio as a measure of an economy's openness (both were obtained from the World Bank Central Database), the Kaufmann et al. (2010) overall indicator of public governance quality, the degree of integration in prudential, business conduct and overall financial sector supervision of Melecky and Podpiera (2012), a central bank political and economic independence indicator, and an indicator for previous financial crisis experience (also from Melecky and Podpiera, 2012). A list of the final set of economic, financial and institutional development indicators that we used is provided in Table 3.

\subsubsection{Stylised facts of the data}

To provide an overview of some of the stylised facts of our data set, we show plots of the aggregate time series properties of the main macroeconomic variables of interest to us in Figures 1 and 2. These plots display the cross-sectional averages (measured by the cross-sectional median) of credit, GDP, the GDP Deflator and the credit-to-GDP ratio.

The plots in Figure 1 show that over the 1980 to 2010 period, credit experienced much stronger positive growth than GDP and the GDP Deflator series. ${ }^{29}$ This is most clearly seen from the growth rates of the series shown in Panel (b) of Figure 1. The average growth rates across countries were $0.6793 \%$ and $1.0689 \%$, respectively, for GDP and the GDP Deflator, while for credit the corresponding growth rate was $2.6115 \%$, which is about $1 \%$ larger than growth in nominal GDP (growth in GDP and the GDP Deflator combined). Credit growth is also ap-

\footnotetext{
${ }^{28}$ Details regarding the computation of the filter are available from the Census Bureau's website available at: http://www.census.gov/srd/www/x12a/.

${ }^{29}$ Note here that we are using two different axes scalings in the plot of the level series in Panel (a) to highlight the evolution of the series. Credit uses the right axis. GDP and the GDP Deflator use the left axis. Also, recall that GDP is (the log of) real GDP and that credit is (the log of) nominal credit. When comparing the growth rates of credit to GDP and the GDP Deflator, we should thus combine the latter two series to get the corresponding nominal GDP figure. The reason why we plot the GDP and GDP Deflator series separately is to highlight some of the differences between them.
} 
proximately twice as volatile as growth in GDP and the GDP Deflator. ${ }^{30}$

The volatility of all three series increased at the end of the sample, that is, after 2008. In 2009:Q2, average credit growth plunged to a value of close to zero $(0.0791 \%)$ from a value of nearly 5 percent two years earlier (4.7872\% in 2007:Q2). Economic activity dropped also quite severely from its peak in 2008:Q2. GDP growth was negative for four consecutive quarters (from 2008:Q3 to 2009:Q2), with 2008:Q3 and 2009:Q1 being two particularly bad quarters, where average contractions were $1.7548 \%$ and $1.9339 \%$ per quarter. In contrast, the periods of greatest credit expansion, where credit demand was seemingly detached from the needs of the real economy (ie., credit expansions were not accompanied by corresponding increases in output and/or the price level) are the late 1980's (from 1987:Q1 to 1989:Q4), the period just before the global financial crisis (from 2005:Q4 to 2008:Q2), and also, albeit to a lesser extent, the mid to late 1990's (from 1995:Q4 to 1998:Q2).

From the time series evolution of the credit, GDP and GDP Deflator series shown in Panel (a) of Figure 1, one can broadly identify three distinct phases (or cycles) prior to the global financial crisis. ${ }^{31}$ The first phase is from 1980:Q1 to approximately the beginning of 1990, the second phase is roughly from the beginning of 1991 to approximately the mid to end of 1994, and the third phase is from 1995 to the mid of 2008. The end of the first phase is marked by the peak in GDP in 1990:Q1, with peaks in credit and the GDP Deflator series trailing somewhat in 1991:Q4 and 1992:Q1, respectively. GDP growth remained rather flat over the second phase from 1990:Q1 until 1994:Q1, where a number of industrial and emerging economies experienced recessions or episodes of stagnant growth. ${ }^{32}$ Following this period, GDP growth largely returned to levels experienced before the 1990's.

The three distinct phases are also evident in the GDP Deflator series. The trend in the GDP Deflator series is noticeably steeper in the first phase than in the third phase. This is consistent with the high levels of inflation that were experienced in the 1980's in many industrial and emerging economies. The third phase seems to coincide with the gradual introduction of explicit or implicit inflation targeting, with inflation rates declining noticeably after 1996. The second phase shows signs of very low inflation, lasting approximately until the end of 1995 . For the credit series, the three distinct phases appear to be considerably weaker, with credit growing seemingly at a linear rate. However, credit did contract from its first peak in 1991:Q4 for two consecutive periods before it started expanding again at a rate similar to the one experienced before 1991:Q4.

The plots in Figure 2 show the time series evolution of the cross-country averages (medians)

\footnotetext{
${ }^{30}$ The standard deviations are $1.0195 \%, 0.5332 \%$ and $0.5447 \%$, respectively for these three series.

${ }^{31}$ The three phases are easily seen in the time series plots of the GDP and GDP Deflator series, but are harder to identify from the credit series which seems to increase more or less monotonically. Credit peaked in 1991:Q4 and then declined for two consecutive quarters and started to increase again from 1992:Q3 onwards.

${ }^{32}$ For instance, the US had a recession in 1990, while Germany, France, Italy and Spain had recessions in 1992 (see Table 1 in Jorda et al., 2012).
} 
of the credit-to-GDP ratio, together with $25^{\text {th }}$ and $75^{\text {th }}$ cross-sectional quantiles. The plot of the level series of the credit-to-GDP ratio shown in Panel (a) of Figure 2 portrays overall an obvious and pervasive positive trend. This positive trend is then sharply reversed at the end of the sample period, with 2009:Q1 marking the peak of the series. From 2009:Q1 to 2010:Q3 a strong negative trend in the credit-to-GDP ratio is visible. This negative trend is consistent with the fact that in the aftermath of the 2008 crisis, banking systems worldwide went into a period of lending freeze and started deleveraging. One can also see from Panel (a) that there were periods with different rates of growth in the credit-to-GDP ratio. For instance, over the early to mid 1980's, the credit-to-GDP ratio appears to be rather stable, while a fairly consistent positive trend is visible from the late 1980's to the end of 1999. From about 2000 until the mid of 2004, a mild positive trend can again be seen, with the period thereafter showing a much stronger positive trend, until the peak of the series in 2009:Q1.

Note that it is common to assume that the credit-to-GDP ratio is a stationary series, due to the view that nominal credit and nominal GDP (GDP plus the GDP Deflator) should form a cointegrating relationship, with the income and price elasticities of credit being equal to unity. ${ }^{33}$ Nevertheless, one can see from Panel (a) of Figure 2 that the credit-to-GDP ratio is a trending variable, indicating that credit grows considerably faster than (nominal) GDP. ${ }^{34}$ The upward trend in the credit-to-GDP ratio is coherent with the view of on-going technological change and financial deepening, which typically results in a decline in credit velocity.

Since the nature of the trend in the credit-to-GDP ratio could be stochastic, that is, driven by a unit-root process with drift rather than by a stationary series plus a linear time trend, we implement two different unit-root tests to verify the statistical properties of the trend. We allow for a trend as well as an intercept in the specification of the model under the alternative hypothesis. The two tests that we implement are the Levin et al. (2002) test which assumes a common unit-root across countries under the null hypothesis, and the Im et al. (2003) test which assumes individual unit-roots. The $p-$ values from these two tests are 0.2609 and 0.2825 , respectively, indicating that the unit-root null hypothesis cannot be rejected at conventional significance levels. ${ }^{35}$

The quarter-to-quarter change in the credit-to-GDP ratio plotted in Panel (b) of Figure 2 shows that the variation of credit-to-GDP growth (at the cross-country level) is noticeably larger in the second half of the sample, ie., from 1995 onwards. In the mid 1990's, the diverse adoption

\footnotetext{
${ }^{33}$ This is the prediction from the quantity theory of Friedman (1956) in money demand models. Other money demand models, such as the transaction model of Baumol (1952) and Tobin (1956) and the precautionary model of Miller and Orr (1966) predict lower values of the income elasticity of money of $1 / 2$ and $1 / 3$, respectively.

${ }^{34}$ This does not need to be a global result, as it seems unlikely from a theoretical perspective that the rate of growth of credit should be permanently disconnected from the underlying credit needs of the economy. However, this observations is true over our sample period.

${ }^{35}$ This is for the full sample period from 1980:Q1 to 2010:Q3. When we consider the shorter time frame excluding the downward trending period in the credit-to-GDP ratio from 2009:Q1 to the end of the sample, the "non-rejection" of the unit-root null hypothesis is even stronger, with $p$-values of 0.4340 and 0.4493 , respectively, for these two tests. The lag order was select using the modified AIC criterion, allowing for a maximum of up to 4 lags.
} 
of new technologies in the banking sector across countries, such as the use of credit cards, lines of credit, revolving credit etc., took place, which could be some of the underlying economic factors explaining this increased dispersion. There were also waves of financial crises, mainly hitting emerging market economies that may have added to the dispersion of the series. ${ }^{36}$ In the late 2000's, the use of large scale securitization of credit and the staggered spill-over effects from the global financial crisis to different regions of the world seem to have contributed to the widening in the cross-country distribution up until 2009. After 2009, the dispersion in creditto-GDP growth has declined somewhat. ${ }^{37}$

\section{Empirical results}

Recall that, as discussed in the Data section, the time-series dimension for some of the countries that we included in the final data set is small. For that reason, we focus on estimating parsimonious models for each country and use the Bayesian Information Criterion (BIC) to determine the appropriate lag order of the ECM in (6). Nonetheless, to ensure that the chosen lag order of the dynamic specification in (6) does not result in any significant serial correlation in the residuals of the fitted models, we initially started with an upper bound of up to three lags in both $Q$ and $P$ in (6) and then reduced the lag order until the BIC was minimized. The chosen lag order for the ECM specification of the ARDL in (6) is $Q=P=1 .^{38}$

\subsection{Visual overview of the cross-country long-run coefficients}

Since we are interested in testing the appropriateness of the unity restriction on the income and price elasticities of credit, we initially inspect the cross-country distribution of the $\hat{\beta}^{g d p}$ and $\hat{\beta}^{\text {def }}$ coefficients to gain some intuition about the distribution before formal statistical tests on the poolability of the long-run parameters are implemented. Histograms and density estimates of $\hat{\beta}^{g d p}$ and $\hat{\beta}^{\text {def }}$ are shown in Panels (a) and (b) of Figure 3. ${ }^{39}$ We used a Gaussian Kernel with an optimal bandwidth selected according to the approach of Shimazaki and Shinomoto (2010) for the density estimates. 95\% confidence intervals, shown by the dashed line, are based on asymptotic standard errors. The number of bins in the histograms was chosen optimally according to the method described in Shimazaki and Shinomoto (2007).

\footnotetext{
${ }^{36}$ The most prominent ones were the Mexican Peso Crisis (1994-1995), the Asian financial crisis (1997-1998) and the Russian crisis (1998).

${ }^{37}$ We suspect that this could be due to systemic risks materializing more or less globally, as every economy was, at least partially, affected by the crisis either directly through credit or indirectly through domestic and/or foreign demand. The dominance of the systemic component of risk marginalised the idiosyncratic component of the cross-country dispersion, leading to convergence of credit-to-GDP growth across countries.

${ }^{38}$ We initially allowed the lag order to differ across the individual countries, but found that the BIC would select too low a lag order for some countries, leading to mild autocorrelation in the residuals. To remove the residual autocorrelation, we decided to fix the lag length to 1 for both $Q$ and $P$ across all countries that were included.

${ }^{39}$ In Panels (a) to (d) in of Figure A.1 in the Appendix, we also plot the empirical distributions of the estimates of the remaining long-run parameters of equation (6).
} 
The distribution of the $\hat{\beta}^{g d p}$ coefficients plotted in Panel (a) of Figure 3 shows visual signs of bi-modality, where the first mode is (approximately) at 2 and the second is at 4 . This preliminary visual analysis suggests that first, at an aggregate or cross-country average level, the income elasticity of credit can be considerably larger than unity. Second, the bi-modality of the density indicates that substantial heterogeneity in the magnitudes of the income elasticity of credit across countries exists. The restriction imposed by the credit-to-GDP ratio when used as the dependent variable in the modelling of equilibrium credit therefore appears to be rejected by the data.

The distribution of the $\hat{\beta}^{\text {def }}$ coefficients plotted in Panel (b) does not show any visual evidence of bi-modality, having a single peak centered at 0 . Although this distribution seems to be more in line with the unit elasticity assumption on the GDP Deflator parameter, considerable variation and a mild left skew in the cross-sectional distribution is evident. This indicates that the cross-sectional mean may not be statistically different from zero. We will return to this discussion when we formally test the significance as well as the unity hypothesis of these parameters.

\subsection{Mean Group (MG) and Pooled Mean Group (PMG) estimation results}

We only report the MG and the PMG estimates of the long-run equilibrium parameters $\beta$, as well as the intercept and the speed of adjustment terms, and do not report results for the shortrun dynamics as these are of no particular interest to us. ${ }^{40}$ We use standard asterisk $\left.{ }^{*}\right)$ symbols in Table 1 and Table 2 to denote significant values at the 10\% $\left(^{*}\right), 5 \%\left({ }^{* *}\right)$ or $1 \%\left({ }^{* *}\right)$ level.

\subsubsection{Mean Group estimates}

The upper part of Table 1 provides the Mean Group estimates of the long-run equilibrium parameters that are computed from the cross-sectional average of each individual country's ARDL regression as $\hat{\boldsymbol{\beta}}_{M G}=N^{-1} \sum_{i=1}^{N} \hat{\boldsymbol{\beta}}_{i}$. Note that the long-run coefficient on GDP is highly significant, centered at a value of 2.9613. Testing the null hypothesis $\mathcal{H}_{0}: \beta_{M G}^{g d p}=1$ against the one-sided alternative $\mathcal{H}_{1}: \beta_{M G}^{g d p}>1$ yields a $t$-statistic of $(2.9613-1) / 0.3260 \approx 6$. This result, hence, provides strong statistical evidence against the unity restriction that the commonly employed credit-to-GDP ratio imposes when used as the dependent variable in the estimation of equilibrium credit.

Insert Table 1

The MG estimate of the GDP Deflator coefficient is 0.2744 with a $p$-value of 0.1927 , indicating that it is not statistically different from zero. Testing the null hypothesis $\mathcal{H}_{0}: \beta_{M G}^{\text {def }}=1$ against a one-sided alternative results in a $t$-statistic of $(0.2744-1) / 0.3161 \approx-2.2955$, which has a corresponding one-sided $p$-value of 0.0109 . The statistical evidence against the unit re-

\footnotetext{
${ }^{40}$ We used a modified version of the specialised GAUSS code of Pesaran et al. (1999) for MG and PMG estimation available from http://www.econ.cam.ac.uk/faculty/pesaran/jasa.exe. The complete regression output from the individual country regressions is large and of no particular interest to us, apart from model checking purposes. We thus do not report the full results here. These are available from the authors upon request.
} 
striction on the GDP Deflator parameter is thus somewhat weaker than for the GDP parameter itself, however, the null hypothesis of $\beta_{M G}^{d e f}=1$ still seems highly unlikely. ${ }^{41}$

The Mean Group estimate of the parameter on the error correction term shown in the bottom part of Table 1 suggests that, on average, deviations of credit from its long-run equilibrium are eliminated with an adjustment speed of around $16 \%$ per quarter. This point estimate is significantly different from zero, with a $t$-statistic of $-6.9381 .{ }^{42}$ The MG estimate of the intercept term is also significantly different from zero, with a point estimate of -1.8644 and a $t$ - statistic of -6.4573 .

The Mean Group estimates of the parameters on the real interest rate, the lending to deposit rate spread, and the alternative cost of borrowing, which make up the velocity equation in (4), all have the expected negative point estimates, indicating that an increase in either of the three borrowing costs leads to a decrease in credit demand. Nonetheless, the results reported in Table 1 show that only the coefficient on the alternative cost of borrowing in foreign currency is significantly different from zero at the $5 \%$ level. In contrast, the $\hat{\beta}^{r r}$ and $\hat{\beta}^{\text {sprd }}$ coefficients have $t$-statistics well below 1 in absolute value, and are thus insignificant.

\subsubsection{Pooled Mean Group Estimates}

Are the long-run parameters that determine equilibrium credit homogenous across countries in our sample? ${ }^{43}$ We investigate this question by estimating the long-run parameters in (6) using the Pooled Mean Group estimator of Pesaran et al. (1999), which restricts some (or all) of the long-run parameters in (6) to be the same across countries. The validity of these restrictions can then be tested with a standard likelihood ratio $(L R)$ test. As our interest focuses on equilibrium credit determined by the $\beta^{g d p}$ and $\beta^{d e f}$ parameters, we only impose the homogeneity restriction on these two parameters, leaving the effect of the real interest rate, the lending to deposit rate spread, and the alternative cost of borrowing in foreign currency, which make up the velocity equation, unrestricted. ${ }^{44}$ These estimates are reported in Table 2.

${ }^{41}$ From a visual inspection of the $\hat{\beta}^{\text {def }}$ distribution plotted in Panel (b) of Figure 3 it may seem surprising that the null of unity is rejected at, for instance, a significance level of $5 \%$, given the relatively large dispersion of $\hat{\beta}^{\text {def }}$ over the -6 and 5 interval. It should be stressed here again that we are testing the Mean Group estimate, which is defined as $\hat{\beta}_{M G}^{\text {def }}=N^{-1} \sum_{i=1}^{N} \hat{\beta}_{i}^{\text {def }}$ with corresponding variance $\operatorname{Var}\left(\hat{\beta}_{M G}^{\text {def }}\right)=[N(N-1)]^{-1} \sum_{i=1}^{N}\left(\hat{\beta}_{i}^{\text {def }}-\hat{\beta}_{M G}^{\text {def }}\right)^{2}$. The variance expression above is simply the variance of the sample mean. With the sample standard deviation of $\hat{\beta}_{i}^{\text {def }}$ being 2.2129 , we can thus see that the MG estimator has a standard error of $2.2129 / \sqrt{49}=0.3161$, where $N=49$ is the number of observations in the cross-section. This leaves a rather tight interval around the point estimate of 0.2744 , making the unity restriction statistically unlikely.

${ }^{42}$ From the cross-country distribution of $\hat{\alpha}$ shown in Panel (d) of Figure A.1 we can see that this result appears to be largely driven by the pronounced left skew in the $\hat{\alpha}$ density. As indicated by the mode of the density, the speed of adjustment estimate is in the -0.10 to -0.05 interval for the majority of countries in our sample, suggesting a more reasonable $5 \%$ to $10 \%$ quarterly adjustment towards the long-run equilibrium.

${ }^{43}$ Note that this is a different hypothesis than testing whether the MG estimates are equal to unity. We are interested in determining whether restricting the long-run coefficients to be the same across the countries is sensible and supported by the data.

${ }^{44}$ We have also restricted all the long-run equilibrium parameters, which evidently is a stronger restrictions. The PMG estimates under this scenarios are $4.4825,-0.4160,-0.0098,-0.0034,-0.0142$ for $\beta^{\text {gdp }}, \beta^{\text {def }}, \beta^{\text {sprd }}, \beta^{\text {acb }}$ and 
The Pooled Mean Group estimates of the restricted $\beta^{g d p}$ and $\beta^{d e f}$ parameters that are reported in Table 2 are, overall, comparable in size to those of the MG estimator. The PMG parameters are, nonetheless, estimated with much greater precision. The standard errors of the MG estimates are about 2.5 and 5 times larger than those of the PMG estimates. Testing the unity restrictions on the PMG estimates of $\beta^{\text {gdp }}$ and $\beta^{\text {def }}$, with the smaller standard errors, yields $t$-statistics of $(3.2672-1) / 0.1201 \approx 18.92$ and $(0.2049-1) / 0.0679 \approx-11.71$, indicating that the PMG estimates are also statistically different from 1.

Looking over the remaining unrestricted coefficients in Table 2, one can notic that the PMG estimates of the three long-run parameters $\beta^{r r}, \beta^{s p r d}$ and $\beta^{a c b}$ are substantially different from those obtained using the MG estimator. The sign of the coefficient on the real interest rate $\left(\hat{\beta}^{r r}\right)$ is now positive and statistically different from zero. The influence of the lending to deposit rate spread $\left(\hat{\beta}^{\text {sprd }}\right)$ has increased 50 times and is also statistically significant. The effect of the alternative cost of borrowing in foreign currency has increased about five fold and remains statistically significant at the 5\% level. The estimate of the speed of adjustment parameter $\alpha$ under the restricted PMG estimator is now only -0.0249 , which is about 8 times smaller in absolute magnitude than the MG estimate reported in Table 1. Additionally, there were four instances where the cross-country restrictions on the $\beta^{g d p}$ and $\beta^{\text {def }}$ parameters lead to positive estimates of the speed of adjustment parameter, thus violating assumption 2 of Pesaran et al. (1999). The above reported differences in the PMG and MG estimates of the unrestricted long-run parameters as well as the speed of adjustment parameter give an indication that the homogeneity restrictions of $\beta^{g d p}$ and $\beta^{d e f}$ being the same across our sample of countries is incompatible with the data.

Since the PMG estimator is inconsistent when the restrictions that are imposed on the longrun parameters are not valid, we perform a poolability test to formally assess the validity of the restrictions. This is implemented by means of an $L R$ test. Note that the PMG estimator imposes $(N-1) \times \tilde{R}$ restrictions on the ARDL model, where in our case $N=49$ and the number of homogeneity restrictions $\tilde{R}$ is equal to 2 . The restricted and unrestricted log-likelihood functions of the PMG estimator are 8089.54 and 8359.71, respectively, resulting in an $L R$ test statistic of over 540. One can see that this corresponds to a $p$-value of effectively 0 for a Chisquared random variable with 96 degrees of freedom. We can conclude, therefore, that the two cross-country homogeneity restrictions on the long-run parameters $\beta^{g d p}$ and $\beta^{d e f}$ are strongly rejected by the data.

$\beta^{r r}$, respectively. The $L R$-statistic is 1085 , with 240 degrees of freedom, so this restriction is strongly rejected by the data. Full results are available from the authors. 


\subsection{Linking the cross-country variation in the income and price elasticities to country-specific development indicators}

To model the cross-country variation in the income and price elasticities of credit, we identify a total of $L=42$ potentially viable explanatory variables (the potential regressors are listed in Section 3.1.2). However, since only $N=49$ cross-sectional observations are available to estimate the regression parameters in (7) and no economic theory exists to guide in the selection of the relevant regressors, we use a statistical approach to determine the best set of explanatory variables. We implement this in two steps. First, we use a Bayesian model averaging (BMA) procedure to narrow down the number of viable candidate regressors to a subset of around $15-20$ variables, where the posterior inclusion probability (PIP) of a variable is used as the selection criterion to determine the most likely regressors. We use a PIP threshold value of $25 \%$ for a variable to be included in the subset. ${ }^{45}$ Second, we use the Lasso penalized regression estimator of Tibshirani (1996) as a variable selection tool to shrink the coefficients of irrelevant or insignificant regressors of the BMA selected subset to zero. ${ }^{46}$

Our main goal is to find the smallest possible set of relevant financial and economic development indicators. To achieve this goal, we make use of the Lasso's ability to shrink small or weakly significant coefficients to zero. Because of the shrinkage that the Lasso imposes in the penalized least squares estimation, parameter estimates are (intentionally) biased. For this reason, once the relevant set of final regressors has been determined with the Lasso procedure, we use the Ordinary Least Squares (OLS) estimator to obtain unbiased estimates of the regression parameters that are not shrunk to 0 in (7).

Note that we follow the same variable selection or reduction procedure to model the crosscountry variation in the $\hat{\beta}^{d d p}$ as well as in the $\hat{\beta}^{\text {def }}$ coefficient. We thus only report the BMA and Lasso regression results for the $\hat{\beta}^{g d p}$ coefficient in this section and provide equivalent results for the $\hat{\beta}^{\text {def }}$ coefficient in the Appendix to conserve space. Also, we will initially refer to the regressors in the preliminary discussions of the BMA and Lasso estimations in Section 4.3.1 and

\footnotetext{
${ }^{45}$ This value may seem low, nonetheless, the purpose of the BMA procedure here is to perform a first round of "pruning" rather than finding the final model. Eicher et al. (2011) have recently used a PIP value of 50\% as the variable inclusion threshold in a growth regression context to determine the "Number of Effective Regressors" (see Figure 1 on page 38). One could thus naturally adopt that value here as well or even set the cut-off mark higher. Nonetheless, we do not follow such an approach here and use the Lasso penalized regression estimator instead in a second step to further "shrink" small or irrelevant coefficients to zero.

${ }^{46}$ It should be clear that the posterior mean of the BMA procedure under the given priors that we use is analogous to a Ridge regression estimator, which is also a penalised regression estimator like the Lasso, with the penalty function being the sum of squared coefficients rather than the sum of absolute coefficients. Nonetheless, one important difference between the Lasso and the Ridge regression estimator is that the Ridge estimator cannot shrink coefficients to zero, but only to small values to reduce the importance of these variables. This means that all variables are included in the regression, which we want to avoid, given the large number of potential regressors. The advantage of the Lasso is that it shrinks unimportant variables to zero, thereby acting as a variable selector. We should also point out here that the reason why we use BMA in the first step rather than using the Lasso on the full set of 42 potential regressors is that we ran into numerical problems when implementing the penalised regression procedure. We therefore found it sensible to reduce the number of potential regressors to a smaller subset first and then proceed with the Lasso.
} 
Section 4.3 .2 by their short names listed in the first column of Table 3 and Table $4 .{ }^{47}$ We discuss the economic meaning of the regressors and their significance for the final selected models in detail in Section 4.3.3.

\subsubsection{Selecting the subset regressors}

We follow the empirical BMA literature and stay within the natural conjugate prior class for computational simplicity, thereby avoiding the need to use simulation methods to compute marginal likelihoods. We use a Normal (Gaussian) prior for the regression coefficients with a prior mean of 0 and Zellner's $\mathrm{g}$ - prior for the variance, so that closed form marginal likelihoods can be computed. That is, for a given model (ie., set of included regressors), we have the prior on the regression parameters being $\phi^{g d p} \mid \sigma_{\varepsilon}^{2} \sim N\left(0, \sigma_{\varepsilon}^{2} g\left(Z^{\prime} Z\right)^{-1}\right)$, where $Z$ is the $(N \times L)$ design matrix representation of the regressors $z_{\ell i}$ in (7) and $\mathrm{g}$ is a prior hyperparameter. ${ }^{48}$

A well known advantage of using the $\mathrm{g}$-prior setup is that only the hyperparameter $\mathrm{g}$ needs to be specified by the user. We follow Fernandez et al. (2001) and set $g=\max \left(N, L^{2}\right)$, which in our set-up yields $g=L^{2}$. We further use uniform priors on the model probabilities. This choice results in an expected model size of $L / 2=21$ variables. It is evident that having an expected number of 21 regressors in a cross-sectional regression with 49 observations is still rather unsatisfactory. Nevertheless, the uniform prior was used with the intention to reduce the number of relevant variables to a subset, and not to the final set of relevant development indicators. Our choice of the model prior is thus a conservative one, in the sense that we prefer a medium sized expected model size to one that shrinks the number of variables more aggressively.

As there are $2^{42}>4.3 \times 10^{12}$ possible (linear) regression models that can be created with 42 potential regressors, we use the Model Composition $\mathrm{MCMC}\left(\mathrm{MC}^{3}\right)$ algorithm of Madigan and York (1995) to generate draws from model space. ${ }^{49}$ We run a chain of 75 million iterations, where the first 25 million are discarded as burn-in draws. We check the convergence of the (model space) Markov chain by computing the correlation between the model iteration counts and analytic posterior model probabilities for the best 5000 models. This correlation is well over $99 \%$, indicating that the Markov chain on the model space has converged. The PIPs of the included variables in the BMA procedure, together with a brief description of the 42 variables included, are reported in Table 3. The results are sorted by largest to smallest PIP value, with the dashed horizontal line marking the $25 \%$ PIP cut-off value.

Insert Table 3 $\leftarrow$ about here

The posterior inclusion probabilities reported in Table 3 show that the prudential1 and cba_economic variables have the highest inclusion probabilities with values close to $100 \%$, indicating that these two variables are included in almost every regression model that is fitted. Two other important variables in terms of high PIPs are the crisis and the cba-political variables with PIPs of $90 \%$ and $87 \%$, respectively. Below the cba_political variable, a noticeable drop

\footnotetext{
${ }^{47} \mathrm{~A}$ more detailed description of these variables is provided in the second column of these tables.

${ }^{48}$ See Koop, 2003 pages $269-273$ for more details regarding this set up and a general overview of BMA.

${ }^{49}$ See also Koop, 2003 pages 269 - 273 for more details regarding this algorithm.
} 
in the PIP size of around $20 \%$ occurs, with the next three important variables being s02cgp0, s13ifs0, and s01ifs0 with PIP values of $68 \%, 63 \%$ and $60 \%$, respectively. The eca indicator variable has a lower PIP of around 54\%. Another two noticeable drops in the PIPs follow the eca variable, of around 10\% each, where the PIPs drop from $54 \%$ to $45 \%$ and then further to $34 \%$ for the s01ess 0 variable. When using a $25 \%$ cut-off mark in the PIPs, the governance 1 variable is the last variable to be included in the resulting subset of 20 variables. In this subset of 20 variables, there are 12 variables that have PIPs of less than $50 \%$ and 8 variables have PIPs of less than $30 \%$.

\subsubsection{Shrinking the subset regressors}

We employ the Lasso penalized regression estimator of Tibshirani (1996) as a variable selection tool to further reduce the subset of development indicators selected with the $25 \%$ PIP cut-off criterion from the BMA procedure. ${ }^{50}$ The value of the "tuning" or "complexity" parameter that controls the amount of shrinkage in the penalised regression problem is chosen by " $k-f o l d$ " cross-validation, where the optimality criterion is (minimizing) the mean squared error (MSE). Since our sample size consists of $N=49$ cross-sectional observations, we use a " $k$ " value of 5 in the cross-validation procedure, which corresponds to around $10 \%$ of the sample size. ${ }^{51}$ The results of the Lasso penalized regression estimator are reported in Table 4. Since we are primarily interested in determining which coefficients are relevant, ie., not shrunk to zero, we only report the Lasso point estimates, where we use the notation " $\Rightarrow 0$ " in Table 4 to denote coefficients that were shrunk to 0 .

Table 4 shows that 13 of the total of 20 subset development indicators are shrunk to 0 . The variables that are selected by the Lasso are the top five variables in terms of the PIPs obtained from the BMA procedure of Section 4.3.1, namely, the prudential1, cba_economic, crisis, cba_political, and s02cgp0 variables, as well as the s01ifso and eca variables..$^{52}$

\subsubsection{Results of the cross-country regression models}

Since the Lasso estimator yields biased parameter estimates due to the penalty term that is included in the estimation to impose the shrinkage, we run OLS based cross-country regressions of $\hat{\beta}^{g d p}$ and $\hat{\beta}^{d e f}$ on their individually selected subset of development indicators to obtain unbiased estimates of these parameters. ${ }^{53}$ These regression results are reported in Table 5. ${ }^{54}$

Insert Table 5 $\leftarrow$ about here

Overall, both regression results reported in Table 5 show that a reasonable cross-sectional

\footnotetext{
${ }^{50}$ See Zou (2006), Zhao and Yu (2006) on how the Lasso can be used as a consistent variable selector and also Section 3.4 in Chapter 3 of Hastie et al. (2009) for a general textbook type treatment of the Lasso.

${ }^{51}$ Note that $k$ is frequently set to values of either 5 or 10 (see Section 7.10 in Hastie et al., 2009 on this and also for more details regarding cross-validation in general).

${ }^{52}$ It is interesting to observe that the s01if so variable is not shrunk towards 0 by the Lasso estimator despite of its coefficient being rather small in magnitude.

${ }^{53}$ Recall that we used the Lasso as a variable selection tool to get the smallest possible set of "important" regressors. Given that we have found the smallest set of important regressors, we use OLS to obtained unbiased estimates of
} 
fit is attained, with about $45 \%$ and $53 \%$ of the variation in $\hat{\beta}^{g d p}$ and $\hat{\beta}^{d e f}$ explained by the individually selected regression models. Tests of the overall significance of the models yield $F$-statistics of 4.75 and 6.22 , with corresponding $p$-values well below $1 \%$ in terms of significance. We use the Breusch-Pagan LM test to test for heteroskedasticity in the residuals. The results of this test are reported next to the "BP Heteroskedasticity" entry in Column 2 of Table 5. For all regressions, no statistical evidence of heteroskedasticity is detected. ${ }^{55}$

\subsection{Discussion of the cross-country regression results}

We now discuss the economic relevance of the variables that determine the cross-country variation in $\hat{\beta}^{g d p}$ and $\hat{\beta}^{d e f}$. To facilitate the discussion, we group the variables into blocks relating to supply side, demand side, and institutional factors.

\subsection{1. $\hat{\beta}^{g d p}$ regression}

Supply side factors: The Private Credit to GDP ratio (s01ifs0), which is a measure of a country's financial depth, has a positive impact on the income elasticity of credit $\left(\hat{\beta}^{g d p}\right) .{ }^{56}$ This suggests that, as a country's financial system develops, it becomes more responsive (sensitive) to changing credit needs in the economy ( $\hat{\beta}^{g d p}$ increases). The financial crisis experience dummy (crisis) affects the income elasticity of credit negatively. Countries that have experienced a financial crisis in the past have a roughly 50\% lower income elasticity of credit than the Mean Group estimate across all countries, which is around 3. This indicates that economies with crises experience are more conservative in increasing credit demand and supply when economic activity is expanding. Also, it is likely that some of our sample countries that have experienced a financial crisis in the past may have undergone periods where credit was dropping much faster than GDP, irrespective of the credit requirements of the economy.

Demand side factors: The effect of the Number of Branches per 100,000 Adults (s02cgp0) on the income elasticity of credit is -4 . This is an interesting result. In an economy, where customers rely on face-to-face interactions with bank staff, the Number of Branches variable measures the access to finance, where a higher number suggests easier access to finance is available. Nonetheless, with the advent of internet based banking and credit availability, a decrease in the income elasticity of credit with an increasing number of branches may in fact capture the effect of financial development of the economy. Many advanced economies experienced a reduction

the parameters.

${ }^{54}$ Standard asterisk $\left({ }^{*}\right)$ notation is again used to denote $10 \%\left({ }^{*}\right), 5 \%\left({ }^{* *}\right)$ and $1 \%\left({ }^{* * *}\right)$ levels of significance. Also, as a robustness check to the regressions that are reported in Table 5 of the individually selected subset of relevant regression indicators for $\hat{\beta}^{g d p}$ and $\hat{\beta}^{\text {def }}$, we show regression results for the union of the individually selected indicators for both dependent variables in Table D.3 in the Appendix.

${ }^{55}$ Due to the lack of any evidence of heteroskedasticity, we simply report homoskedastic standard errors in Table 5. Further details, including visual plots of the fitted and actual series, as well as the residual distributions, are provided in the Appendix.

${ }^{56}$ Note here that Private Credit to GDP is measured in \%, thus at a base value of 100 . This means that an increase of $50 \%$ in the ratio, ie., from 100 to 150 , results in an increase in $\hat{\beta}^{g d p}$ from 3.21 to 4.815 . 
in the number of bank branches over the last $10-15$ years due to efforts made by financial institutions to reduce staffing costs. Furthermore, the popularity of, and demand for, internet banking has increased substantially. Alternatively, the negative effect of the Number of Branches on the income elasticity of credit can be explained by portfolio diversification where agents replace credit with other financial services to increase the diversity of their financial portfolios. Such a strategy is often pursued in an effort to manage risks more effectively by using market insurance and investment diversification instead of credit to reduce the risk of potential portfolio losses (see also Ehrlich and Becker, 1972 for additional details).

Institutional factors: Greater Integration of Prudential Supervision (prudential1) increases the flexibility of the financial system to respond promptly to changes in credit demand in the economy. This is due to the effect that Greater Integration of Prudential Supervision has on increasing competition by creating a more harmonised and transparent regulatory framework across different financial sub-sectors. Both, Central Bank Economic and Political Independence (cba_political and cba_economic) have a positive impact on the income elasticity of credit. Independent central banks tend to respond more timely and appropriately to prevailing business as well as credit cycle conditions in the economy, to align these with the targets of the central bank. GDP, or its deviation from potential/target, has traditionally been one of the two main macroeconomic variables that a central bank reacts to. ${ }^{57}$ More recently, credit has also become either directly or indirectly part of the reaction function of a central bank (see Cúrdia and Woodford, 2010 and Christiano et al., 2007 for recent evidence). ${ }^{58}$ The coefficient on the ECA regional dummy has a positive point estimate, suggesting a higher income elasticity of credit in the ECA region. The ECA coefficient is, nonetheless, estimated rather imprecisely. This indicates that considerable variation in the average response of credit to changes in GDP exists within the ECA group of countries. ${ }^{59}$

\subsection{2. $\hat{\beta}^{\text {def }}$ regression}

Supply side factors: The Cost to Income Ratio (s05bsk0), which measures the cost effectiveness of banks, has a positive effect on the price elasticity of credit. This indicates that more competitive banking systems with smaller profit margins respond with more flexibility to changes in credit demand as the average price level in the economy varies. The coefficient on the financial crisis dummy (crisis) shows that the experience of a financial crisis increases the price elasticity of credit. This is an interesting result. There could be two reasons for this. First, from

\footnotetext{
${ }^{57}$ The other macroeconomic variable is inflation. See, for instance, the enormous literature on Taylor rules, or the original formulation of the Taylor rule as in Taylor (1993).

${ }^{58}$ See also Cho and Moreno (2006) and Buncic and Melecky (2008) for examples of monetary policy reactions functions in a small New Keynesian model for the US and a small open economy version for Australia.

${ }^{59}$ This positive estimate could be rationalized by greater convergence of institutional and legal frameworks in the ECA region due to the EU integration process, which facilitates higher interconnectedness in trade, labor, and also capital (financial) flows. The interconnectedness helps transmit both positive and negative shocks and thus increases the sensitivity of credit to both positive and negative income shocks. We do not approximate the time-varying degree of regional integration in ECA explicitly and leave this task for future research.
} 
an empirical perspective, countries may have experienced periods of deflation in crisis times due to a negative wealth effect on prices. That is, prices could be falling together with credit, resulting in a positive price elasticity of credit. Second, from a moral hazard perspective, if excessive risk taking that leads to a financial crisis is not adequately punished, then otherwise conservative agents may pursue an active strategy to take on more risky investments through asset purchases, leading to inflated asset prices. Investments are generally (or at least can be) financed through bank credit, which can then result in a positive relation between credit and prices.

Demand side factors: The price elasticity of credit is positively related to the Number of Branches per 100,000 Adults (s02cgp0). This suggests that easier access to credit enables the private sector to adjust credit demand to changes in the average price of a transaction more easily. Outstanding Domestic Private Debt Securities (s01bis0), on the other hand, decrease the price elasticity of credit. This result can arise as private agents in more developed domestic debt markets may rely less on bank credit and can easily substitute bank credit by issuing debt in the domestic capital market.

Institutional factors: Integration of Prudential Supervision (prudential1) as well as Central Bank Political and Economic Independence (cba_political and cba_economic) have negative coefficients, suggesting that an increase in either one of these three indicators leads to a reduction in the price elasticity of credit. ${ }^{60}$ All three indicators measure how independent monetary policy and, in many cases, macroprudential policy are from political pressures and industry lobbies. As highlighted above, many independent central banks now have explicit targets for GDP growth, inflation and also credit growth. An increase in central bank independence in conjunction with a more harmonised and comprehensive supervisory structure thus gives the central bank more autonomy to adjust policy rates in response to deviations of the control variables from their targets.

\subsection{A comparison of equilibrium credit across NMS11 countries}

To illustrate how our proposed structural approach to estimate equilibrium credit compares with the HP filter based statistical approach of the Basel III regulatory framework, we construct credit gaps for ten new EU member states (NMS10): Bulgaria, the Czech Republic, Estonia, Hungary, Latvia, Lithuania, Poland, Romania, the Slovak Republic, and Slovenia. We also add Croatia to this group and refer to it as "NMS11" from now on. We focus on these 11 selected countries, as they represent a relatively homogenous group and face similar challenges related to their banking sector structure and its cross-border integration.

\footnotetext{
${ }^{60}$ Notice here that the parameter estimates of the two central bank independence measures are -4.82 and -4.85 , respectively. It may thus seem that the similarity of the two coefficients is driven by high collinearity of these two measures. This is, however, not the case here, as the sample correlation between the series is only 0.22 . These two variables therefore measure different parts of Cental Bank independence and its impact on $\hat{\beta}^{\text {def }}$.
} 
More generally, the NMS11 have harmonized legal and institutional frameworks, because they have implemented the aqui communitaire of the EU, and have opened trade and capital flows in accordance with EU policy. Compared to older EU member states, the NMS11 are also faced with the challenge to further deepen their banking systems and advance financial inclusion in the use of formal credit and deposits. For instance, Romania's deposits-to-GDP ratio and credit-to-GDP ratio stood at 31 and 38 percent, respectively in 2011 (see Al-Hussainy et al. 2011). Although similar ratios for Slovenia are considerably higher at 58 and 90 percent, they are still far from the levels of, for instance, Germany, which are at 117 and 106 percent.

Nonetheless, the selected group is also heterogeneous in some respects, most notably in the use of foreign savings to finance domestic lending. For example, the loan to deposit ratio of Latvia's and Slovenia's banking systems stood at 218 and 154 percent in 2011, whereas the same ratio for the Czech Republic and the Slovak Republic stood at 87 and 90 percent. Further, while all of the NMS11 experienced a banking crisis during the 1990's, only Hungary, Latvia, and Lithuania have experienced a banking crisis after 2008 (see Table A.1 on page 24 in Laeven and Valencia 2012). Because of the similarities in legal and institutional frameworks and the differences in financial sector structure, we believe that the small group of NMS11 is rich enough to illustrate our structural approach and to contrast it with the existing statistical approach of Basel III.

To construct the credit gap based on the statistical approach, we follow the Basel III guidelines and compute HP filtered trend estimates of the Credit-to-GDP ratio using a "smoothing" parameter value of $400000 .{ }^{61}$ We then subtract the filtered equilibrium credit from credit. The credit gap based on our structural approach is obtained by subtracting the estimate of equilibrium credit computed in (8) from credit. To facilitate comparison between the two different procedures, we standardize the volatility of the structural credit gap to be equal to that of the HP filtered credit gap. Estimates of both credit gaps for the NMS11 countries, together with vertical lines marking the $2 \%$ and $10 \%$ thresholds of the Basel III guidelines, are shown in Figure 4 .

The HP filtered credit gaps of Basel III (dashed blue line) and our proposed structural credit gaps (solid red line) for the NMS11 countries show some interesting similarities, but also very important differences. More specifically, the two credit gap measures track each other reasonably closely for Bulgaria, the Czech Republic and Lithuania, and have, at least overall, similar trends for Hungary, Romania and Slovenia. The Basel III measure, nevertheless, seems to produce rather volatile credit gaps for Hungary, Romania and Slovenia. For Estonia, Poland and also, albeit to a smaller degree, for Latvia, the two measures seem to track each other reasonably closely for roughly half of the sample period, but then produce very different credit gaps for the second half of the sample. For the Slovak Republic as well as for Croatia, the two credit gaps are different for nearly the entire sample period.

\footnotetext{
${ }^{61}$ See page 10 in BCBS (2010) for the exact details of this computation.
} 
Since the plots of the two credit gaps in Figure 4 do not provide any intuition about the economic mechanism that is defining the credit gaps, we provide a somewhat more detailed overview of the economic conditions that prevailed in the individual NMS11 countries. It is not our intention here to give a full and detailed discussion of these conditions, but rather would like to highlight the underlying mechanisms that led to the credit gaps that are plotted in Figure 4. With regards to deviations of GDP and the GDP Deflator from their potential or trend levels, visual inspection shows that for all NMS11 countries except for the Czech Republic, the GDP Deflator stayed more or less close to its trend level. For this reason, we focus the discussion below mainly on the evolution of credit, GDP and potential GDP, and make little or no mention of the effect of the GDP Deflator (and potential GDP Deflator) on our structural credit gap. ${ }^{62}$

The Czech Republic, Bulgaria and Lithuania had credit levels more or less at or below equilibrium until mid 2006 (beginning of 2007 for Bulgaria), when credit began to expand more aggressively in all three countries. This expansion in credit came together with an expansion in economic activity, where GDP moved well above its potential in 2006:Q2, 2007:Q2 and 2006:Q2, respectively for these three countries. GDP peaked in 2008:Q2 for all three countries and fell quickly below potential by 2008:Q4. Credit growth started to decline already in 2008:Q2 for the Czech Republic, dropping from a growth rate of 5.7\% in 2008:Q1 to about 2.3\% in 2008:Q2 and remained at similar levels until 2009:Q1. After 2009:Q1, credit growth dropped even further to about $0.5 \%$ and stayed at this level until the end of the sample.

The Czech Republic experienced an episode of high inflation from 2003:Q4 until 2005:Q2, as is evident from GDP Deflator growth being well above potential. This coincided with below potential growth in GDP. Both credit gap measures were negative over this time period, suggesting a lack of credit provision in the economy. For Bulgaria, the drop in credit growth came in 2008:Q4 (2.2\%) from a level of $6.8 \%$ in 2008:Q3, declining to a growth rate of less than $1 \%$ by 2009:Q1. In Lithuania, credit peaked in 2007:Q4, attaining a growth rate of 10.3\%, which then dropped to $4.9 \%$ by 2008:Q2. Since 2009:Q1, credit has contracted.

Hungary, Romania and Slovenia all started with fairly low levels of credit and then proceeded to expand rather aggressively. Hungary had fairly stable credit growth over the period of the financial crisis, averaging around 6\% quarterly growth from 2007:Q2 until 2009:Q1, with only one quarter of negative growth in 2008:Q2. Credit growth then turned negative in 2009:Q2 (-9.8\%). GDP had been expanding at potential from 1996:Q2 until about 2006:Q4, where GDP growth started to accelerate mildly, being above potential until 2008:Q2. Since then, GDP has dropped significantly below potential, with quarterly contractions in GDP averaging 3\% from 2008:Q4 until the end of the sample.

\footnotetext{
${ }^{62}$ We provide add-on material at http:/ / www. danielbuncic.com/pdf/NMS11_addon.pdf that shows not only the credit gaps computed from our proposed structural model, but also the individual components such as GDP and the GDP Deflator, as well as their potential (or trend levels). The add-on material further contains a visual evaluation of the fit of the ARDL model that is estimated, showing actual and fitted values for $\Delta c r_{t}$, ie., the differenced series, and also for the level series $\mathrm{cr}_{t}$, including plots of the residuals, the residual distribution, the cumulative sum (cusum) of the residuals and the squared residuals.
} 
In Romania, credit demand was rather strong over the entire sample period. Credit growth averaged 12\% over the period from 2000:Q4 to 2008:Q3. From 2008:Q4, credit growth dropped sharply to well below 2\%, being negative in 2009:Q2 and 2010:Q1. The boom in economic activity, where GDP grew much faster than potential, started in 2007:Q3, reaching a peak in 2008:Q3, but then fell rapidly well below potential over the next few quarters. GDP growth was negative for every quarter from 2008:Q4 until the end of the sample in 2010:Q1, with the only exception being 2009:Q3.

Slovenia also experienced fairly stable credit growth, averaging around $4 \%$ per quarter from 1999:Q2 to its peak in 2008:Q2. Output grew largely at potential until 2007:Q1, and then started to expand more rapidly until 2008:Q2, growing at about twice the rate of potential GDP. Since 2008:Q2, GDP growth has been negative for 5 consecutive quarters until the end of the sample in 2009:Q3, falling below potential in 2008:Q4. Credit growth has dropped to more moderate levels of around 1\% or less since 2008:Q4.

For the remaining five NMS11 countries shown in the bottom half of Figure 4, the two credit gaps differ markedly. For Estonia, the two measures tracked one another rather closely from the beginning of the sample until 2006:Q1. From 2006:Q2 onwards, they started to diverge. Initially, there was movement in the same direction, with the structural credit gap, nonetheless, indicating a much larger deviation of credit from equilibrium. In 2008:Q3, a sharp reversal in the direction of the structural credit gap occurred, moving back towards 0 , while the statistical measure of Basel III continued to increase.

Estonia experienced a rather stable average quarterly credit growth rate of $4 \%$ from 1999:Q2 to 2005:Q1. However, from 2005:Q2 to 2007:Q2, credit started to expand much more strongly, reaching an average quarterly growth rate of $8.5 \%$ over this period. ${ }^{63}$ From 2006:Q4, credit started to contract in a near linear fashion, falling by about 1 percentage point per quarter, turning negative in 2008:Q4 and remaining below zero until the end of the sample in 2009:Q2. Economic activity expanded largely along potential output until 2005:Q1. GDP began to grow much stronger from 2005:Q2 until its peak in 2007:Q2, with an average growth rate of nearly 2.5\%. From 2008:Q1 until the end of the sample, not only was average GDP growth negative $(-3 \%)$, but it was negative for every consecutive quarter. ${ }^{64}$ Growth in potential output had also slowed from the earlier quarterly average of around 2\% from 1999:Q2 to 2005:Q1 to about 1\% for the 2005:Q2 to 2007:Q2 period, falling further to less than 0.5\% per quarter from 2007:Q3 onwards.

It is interesting to highlight here that for Estonia, despite the sharp drops in credit (as well as GDP), the credit-to-GDP ratio, which is used in the HP-filtered credit gaps of the Basel III framework, maintained a strong (positive) quadratic trend over the entire sample period, without any

\footnotetext{
${ }^{63}$ There were two instances where quarterly credit growth exceeded 11\% (in 2006:Q2 and in 2006:Q4).

${ }^{64}$ Two particularly bad quarters were 2008:Q4 and 2009:Q1 with GDP growth being $-5.6 \%$ and $-6.9 \%$, respectively.
} 
obvious visual effect of the crisis on the ratio. Given the "weighted moving average" nature of the Basel III statistical rule to compute equilibrium credit from the credit-to-GDP ratio, the credit gap kept rising regardless of the adjustments that had taken place in economic activity. What is particularly discouraging for Estonia is that the Basel III credit gap is procyclical in the sense that it advises macroprudential supervisors to tightened credit even further, although credit growth had already dropped to negative levels, being well below the stable period's average growth rate of $4 \%$. Such a procyclical scenario can occur whenever the contraction in GDP is larger than the contraction in credit, resulting in a steady increase in the credit-to-GDP ratio. ${ }^{65}$

For Poland, the two credit gaps overlap rather well for the first half of the sample, covering the period from 1996:Q2 to 2001:Q2. Credit grew initially above equilibrium from 1996:Q2 until 2000:Q1 and at equilibrium (or marginally above) from 2000:Q1 to 2001:Q2. Part of the initial increase in the gaps is attributed to a mild period of above potential GDP growth from 1999:Q3 to 2001:Q1. Potential GDP declined from above 1.1\% quarter-to-quarter growth in the late 1990s, to less than $0.8 \%$ from 2000:Q1 to 2004:Q2, to above 1\% from 2005:Q1 until the end of the sample in 2006:Q4. The marginally greater decline in the statistical credit gap, relative to the structural one, is due to the comparatively larger slow down in growth in the credit-to-GDP ratio relative to growth in potential GDP.

For Latvia, the two credit gaps match up reasonably well for the first third of the sample (from 1993:Q3 to 2004:Q1), where both series indicate that credit was broadly at, or slightly above, equilibrium levels. From 2004:Q2, the series started to diverge, with the statistical credit gap indicating a marginally higher gap than the structural one. Nonetheless, the series continued to move in the same direction until about 2008:Q1, having similar turning points, most notably the one around 2007:Q1, after which both series started to move back towards 0. From 2008:Q1 onwards, the series began to diverge substantially. The statistical credit gap turned upwards again, thus suggesting an excess of credit provision in the economy, while the structural credit gap continued to drop sharply, falling below 0 in 2008:Q2 and reaching -18 in 2009:Q2.

Latvia started from fairly low credit levels, expanding credit at a pace of around $7 \%$ per quarter over the period from 1999:Q3 to 2004:Q1. The pace of credit growth then increased to around $10 \%$ per quarter from 2004:Q1 to 2007:Q2, after which it began to drop rapidly from $10 \%$ in 2007:Q2, to $5.3 \%$ in 2007:Q3 to $3.4 \%$ in 2008:Q1, falling steadily thereafter until the end of the sample in 2009:Q2. Credit growth was negative for the last three quarters of the sample. Economic activity expanded largely along potential output for the first two thirds of the sample period, that is, until 2005:Q3, where average GDP and potential GDP grew at 1.92\% and $1.98 \%$, respectively. Since then, potential GDP growth has fallen to about 1\% in 2007:Q3, dropping further below 0.5\% from 2008:Q3 until the end of the sample. GDP grew well above potential from 2005:Q4 until 2007:Q3, averaging 2.6\% quarterly growth, but started to fall sharply in

\footnotetext{
${ }^{65}$ Recall that the Basel III credit gap uses current GDP values and also makes the implicit assumption that the income elasticity of credit is equal to unity.
} 
2007:Q4, being negative from 2008:Q1 for every quarter until the end of the sample in 2009:Q2. This disconnect between GDP and potential GDP was accompanied with a period of strong credit growth from 2005:Q2 to 2006:Q3, where average credit growth was 12.95\%.

Regardless of the strong contraction in credit from 2008:Q1 onwards, due to the heavy drop in GDP over the same time period, the credit-to-GDP ratio continued to rise by $30 \%$ from 2008:Q1 to 2009:Q2, resulting in a positive and rising statistical credit gap. Thus, similar to the scenario experienced in Estonia, the statistical credit gap indicated an excess of credit provision in Latvia, despite the already relatively low levels of credit. Once again, a procyclical policy response would be induced if one were to use the statistical credit gap as an indicator of credit provisions, leading to further credit reducing measures being implemented by the macroprudential regulatory authority.

For the Slovak Republic, the difference between the structural and statistical credit gaps is most pronounced in the first half of the sample period. Contrary to most of the other NMS11 countries, the Slovak Republic started with a fairly high credit level. This is reflected in the credit-to-GDP ratio. At the beginning of the sample in 1997:Q2, the credit-to-GDP ratio stood at $20 \%$ and has declined monotonically from this peak to a around 10\% in 2003:Q1, remaining at this level until 2004:Q4. The Basel III statistical credit gap mirrored the steady decline in the credit-to-GDP ratio. The credit gap was not only negative from 1998:Q2 onwards, but it kept declining until 2002:Q1. Since the beginning of 2005, both, the credit-to-GDP ratio as well as the credit gap have been rising monotonically, with the credit gap indicating that credit growth had become excessive since about 2006:Q1, breaking the Basel III 10\% threshold in 2007:Q4.

The structural credit gap has steadily increased from the beginning of the sample in 1997:Q2, breaching the 2\% and 10\% Basel III thresholds in 1998:Q1 and 1999:Q1, respectively, peaking in 2000:Q3, and moving towards 0 thereafter. It remained fairly flat and well below 0 from 2002:Q1 until 2005:Q1, and has increased since 2005:Q2, overlapping very closely with the statistical credit gap of Basel III. Note that the Slovak Republic experienced a banking crisis from 1998 to 2002. Our structural credit gap therefore does identify problems with prevailing credit levels at the beginning of 1998. Nevertheless, it should be clear here that it does not directly qualify as an early warning system indicator, as it may not have been timely enough for macroprudential supervisors to intervene appropriately. ${ }^{66}$

The Slovak Republic started with a fairly low quarterly average growth rate in potential GDP of 0.5\% from 1997:Q2 to 2000:Q2, which steadily increased to around 1.5\% from 2003:Q1 to 2005:Q2, and to 1.95\% since 2006:Q3. Credit growth was positive from 1997:Q2 to 2000:Q3, with an average quarterly growth rate of $1.5 \%$, but then dropped sharply from 2000:Q4, bottoming out in 2002:Q2. Since 2002:Q3, credit started to expand again, mildly at first, but growing

\footnotetext{
${ }^{66}$ One difficulty with the Slovakian data set is that the crisis occurred at the beginning of our sample period. This makes it cumbersome to judge how the structural rule would have performed if another 2-3 years of data prior to the crisis would have been available.
} 
at a quarterly average of about 6\% from 2005:Q2 to 2008:Q1. Note that the predicted income and price elasticities of credit for the Slovak Republic are 3.4 and -1.8 , respectively. Average quarterly growth rates of potential GDP and GDP Deflator were $1.74 \%$ and $0.77 \%$ from 2005:Q2 to 2008:Q1. Using the changes form of the equilibrium credit equation in (9), that is, $\Delta \overline{c r}_{t}^{e q}=\bar{\beta}^{g d p} \Delta \overline{g d p}_{t}+\bar{\beta}^{\text {def }} \Delta \overline{d e f}_{t}$, this implies a predicted change in equilibrium credit of $3.4 \times 1.74-1.8 \times 0.77=4.53$. Thus, credit growth has been about $6 \%-4.53 \%=1.47 \%$ above equilibrium per quarter (on average) from 2005:Q2, indicating a gradual build up of excessive credit provision in the economy.

For Croatia, the two credit gaps were rather different for nearly three quarters of the sample period. The two gaps moved quite closely together from the beginning of the sample in 2000:Q2 until 2002:Q3, indicting positive and increasing credit gaps over this time period. Both gaps peaked around 2003:Q1 and began to move towards 0 (or negative values) thereafter. Nonetheless, the statistical credit gap dropped much faster, turning negative in 2003:Q3, while the structural gap adjusted more gradually reaching its minimum of $-0.04 \%$ in 2005:Q1. Credit grew initially at a relatively fast pace of 5\% (quarter to quarter average) from 2000:Q1 to 2003:Q1 and then dropped to a more moderate rate of 2.7\% from 2003:Q2 until 2005:Q1. Output grew largely in line with potential from 2000:Q1 to 2003:Q1, with average growth in GDP and potential GDP being $1.18 \%$ and $1.2 \%$, respectively, and somewhat below potential at $0.82 \%$ (potential being 1.1\%) from 2003:Q2 to 2005:Q1.

Since 2005:Q2, both credit gaps turned upward again. However, the Basel III measure produced rather volatile up and down swings in the credit gap, crossing the $2 \%$ and $10 \%$ thresholds multiple times and also turning negative numerous times. This volatility in the Basel III credit gap was mainly caused by volatility in GDP. Credit grew steadily at $4 \%$ per quarter form 2005:Q2 to 2008:Q4, and then dropped to 1.4\% in 2009:Q1. Credit growth turned negative in 2009:Q2 and 2009:Q3 (-1.8\% and $-0.85 \%)$, but returned to low positive levels from 2009:Q4 until the end of the sample. GDP growth, on the other hand, was 3.5\% in 2005:Q2, then dropped to $0.75 \%$ in $2005: Q 3$, and remained fairly flat at a quarterly growth rate of around 1\% from 2005:Q3 to 2007:Q3. In 2007:Q4, GDP growth was $-0.12 \%$, jumped to $3.3 \%$ the following quarter, but returned to negative values in 2008:Q2, remaining negative until the end of the sample in 2010:Q2. Excessive credit provision in Croatia since 2008:Q1, as indicated by the structural credit gap, is due to the drop in potential GDP. Although growth in potential output was stable, averaging 1\% from 2000:Q2 to 2006:Q1, it has since then declined rapidly to $0.5 \%$ in 2007:Q3 and to less than $0.1 \%$ average quarterly growth since 2009:Q1.

In summary, this section showed that there can be substantial differences in the credit gap estimates of the Basel III framework and our proposed structural (through-the-cycle) approach, with the Basel III have the deficiency of potentially creating a procyclical estimate of equilibrium credit. 


\section{Conclusion}

Since the 2008 global financial crisis, excessive credit provision, that is, credit in excess of equilibrium credit, has become the focal point for macroprudential supervisors. This paper proposes a structural framework to estimate equilibrium credit which is based on an economy's through-the-cycle transaction demand for credit and which accounts for the effects of economic, financial, and institutional development on credit demand. Our proposed framework consists of three broad stages. We initially estimate country specific estimates of the income and price elasticities from a panel data set of 49 countries covering the time period form 1980 to 2010. We then relate the variation in the cross-country elasticity estimates to a set of relevant economic and financial development indicators. The fitted values from this second stage regression provide conditional mean group estimates of the income and price elasticities, accounting for the different levels of development of the countries in our data set. In a last step, we use the fitted second stage elasticities together with estimates of trend GDP and GDP Deflator values to compute our propose structural through-the-cycle equilibrium credit reference point.

In this paper we also show that the restrictions which the credit-to-GDP ratio implicitly imposes on the income and price elasticities of credit are strongly rejected by the data. We show further that the cross-country variation in the income and price elasticities can be modelled by a set of relevant economic, financial, and institutional development indicators. The main development indicators driving the cross-country variation in the elasticities are: financial depth, access to financial services, use of capital markets, efficiency and funding of domestic banks, central bank independence, the degree of supervisory integration, and the experience of a financial crisis. These results indicate that using the credit-to-GDP ratio to gauge equilibrium credit is inappropriate as it not only imposes restrictions on the data that are invalid but it also ignores the cross-country heterogeneity in the parameters that determine the long-run equilibrium credit relation.

Our empirical findings have important policy implications. Our results show that the Basel III proposal to use the HP filtered credit-to-GDP ratio to compute equilibrium credit may be too simplistic in the sense that it disregards important country specificities of how equilibrium credit changes with financial, economic and institutional development. We provide empirical evidence to show that there can be substantial differences in the credit gaps estimated from Basel III and our proposed structural approach. Country specificities are therefore important and need to be accounted for when equilibrium credit is estimated, especially for developing countries. We also show that there exist instances where the Basel III measure can lead to a procyclical estimate of equilibrium credit, thereby potentially amplifying economic booms and intensifying recessions.

Developing countries have much to lose if they focus too intensely on financial stability and restrict credit provision too severely, as overly restrictive credit provision can hinder financial development and be in the way of economic development in general. 


\section{References}

Al-Hussainy, Ed, Andrea Coppola, Erik Feyen, Alain Ize, Katie Kibuuka and Haocong Ren (2011): "FinStats 2011: A ready-to-use tool to benchmark financial sectors across countries and over time," Mimeo, World Bank.

Arango, Sebastian and M. Ishaq Nadiri (1981): "Demand for money in open economies," Journal of Monetary Economics, 7(1), 69-83.

Basel III (2011): "Basel III: A global regulatory framework for more resilient banks and banking systems (revised version)," Bank for International Settlements. Available from: http:/ / www.bis.org/publ/bcbs189.pdf.

Baumol, William J. (1952): “The Transactions Demand for Cash: An Inventory Theoretic Approach," The Quarterly Journal of Economics, 66(4), 545-556.

BCBS (2010): "Guidance for national authorities operating the countercyclical capital buffer," Bank for International Settlements. Available from: http://www.bis.org/publ/bcbs187.pdf.

Beck, Thorsten, Asli Demirgüç-Kunt and Ross Levine (2000): "A new database on financial development and structure," World Bank Economic Review, 14(3), 597-605.

Beveridge, Stephen and Charles R. Nelson (1981): “A new approach to decomposition of economic time series into permanent and transitory components with particular attention to measurement of the Business Cycle," Journal of Monetary Economics, 7(2), 151-174.

Brissimis, Sophocles N. and John A. Leventakis (1985): "Specification tests of the money demand function in an open economy," The Review of Economics and Statistics, 67(3), 482-89.

Brzoza-Brzezina, Michal (2005): “Lending booms in Europe's periphery: South-Western lessons for Central-Eastern members," Mimeo, National Bank of Poland. Available from: http:/ /129.3.20.41/eps / $\mathrm{mac} /$ papers/0502/0502002.pdf.

Buncic, Daniel and Martin Melecky (2008): "An estimated New Keynesian Policy Model for Australia," The Economic Record, 84(264), 1-16.

(2013): "Macroprudential stress testing of credit risk: A practical approach for policy makers," Journal of Financial Stability, 9(3), 347-370.

Calza, Alessandro, Christine Gartner and Joao Sousa (2001): "Modelling the demand for loans to the private sector in the Euro area," ECB Working Papers No. 055, European Central Bank.

Calza, Alessandro, Joao Sousa and Marta Manrique Simon (2003): “Aggregate loans to the euro area private sector," ECB Working Paper Series No. 202, European Central Bank.

Cho, Seonghoon and Antonio Moreno (2006): "A Small-Sample Study of the New-Keynesian Macro Model," Journal of Money, Credit, and Banking, 38(6), 1461-1481.

Christiano, Lawrence, Roberto Motto and Massimo Rostagno (2007): "Two Reasons Why Money and Credit May be Useful in Monetary Policy," NBER Working Paper No. 13502, National Bureau of Economic Research. 
Cottarelli, Carlo, Giovanni Dell'Ariccia and Ivanna Vladkova-Hollar (2005): “Early birds, late risers, and sleeping beauties: Bank credit growth to the private sector in Central and Eastern Europe and in the Balkans," Journal of Banking and Finance, 29(1), 83-104.

Coudert, Virginie and Cyril Pouvelle (2010): "Assessing the sustainability of credit growth: The case of Central and Eastern European countries," European Journal of Comparative Economics, 7(1), 87-120.

Croushore, Dean and Tom Stark (2001): "A funny thing happened on the way to the data bank: a real time data set for macroeconomists," Federal Reserve Bank of Philadelphia - Business Review, (September/October), 15-27.

Cúrdia, Vasco and Michael Woodford (2010): “Conventional and unconventional monetary policy," Review, Federal Reserve Bank of St. Louis, (May), 229-264.

Dell'Ariccia, Giovanni, Deniz Igan, Luc Laeven and Hui Tong (2012): "Policies for Macrofinancial Stability: How to Deal with Credit Booms," IMF Staff Discussion Note No. 12/06, International Monetary Fund.

Drehmann, Mathias, Claudio Borio, Leonardo Gambacorta, Gabriel Jiminez and Carlos Trucharte (2010): “Countercyclical capital buffers: exploring options," BIS Working Papers No. 317, Bank for International Settlements.

Égert, Balázs, Peter Backé and Tina Zumer (2006): “Credit growth in Central and Eastern Europe - new (over)shooting stars?" ECB Working Paper No. 687, European Central Bank.

Ehrlich, Issac and Garry S. Becker (1972): "Market Insurance, Self-Insurance and Self-Protection," Journal of Political Economy, 80(4), 623-648.

Eicher, Theo S., Chris Papageorgiou and Adrian E. Raftery (2011): “Default priors and predictive performance in Bayesian model averaging, with application to growth determinants," Journal of Applied Econometrics, 26(1), 30-55.

Eller, Markus, Michael Frömmel and Nora Srzentic (2010): "Private sector credit in CESEE: Long-Run relationships and short-run dynamics," Focus on European Economic Integration, 2010(2), 50-78.

Fernandez, Carmen, Eduardo Ley and Mark F. J. Steel (2001): “Benchmark priors for Bayesian model averaging," Journal of Econometrics, 100(2), 381-427.

Friedman, Milton (1956): “The Quantity Theory of Money: A Restatement," in Studies in the Quantity Theory of Money, edited by Milton Friedman, University of Chicago Press Chicago.

Gourinchas, Pierre-Olivier, Rodrigo O. Valdes and Oscar Landerretche (2001): “Lending Booms: Latin America and the world," Economia, 2(1), 47-99.

Hastie, Trevor, Robert Tibshirani and Jerome Friedman (2009): The Elements of Statistical Learning: Data Mining, Inference, and Prediction, $2^{\text {nd }}$ Edition, Springer New York.

Hodrick, Robert and Edward C. Prescott (1997): "Post-war US business cycles: A descriptive empirical investigation," Journal of Money, Credit, and Banking, 29(1), 1-16.

Hofmann, Boris (2004): “The Determinants of Bank Credit in Industrialized Countries: Do Property Prices Matter?" International Finance, 7(2), 203-234. 
Humphrey, David, Aris Kaloudis and Grete Øwre (2004): "The future of cash: falling legal use and implications for government policy," International Financial Markets, Institutions and Money, 14(3), 221233.

Im, Kyung So, M.Hashem Pesaran and Yongcheol Shin (2003): "Testing for unit roots in heterogeneous panels," Journal of Econometrics, 115(1), 53-74.

Jorda, Oscar, Moritz Schularick and Alan Taylor (2012): "When Credit Bites Back: Leverage, Business Cycles and Crises," Working Papers No. 1224, University of California, Davis, Department of Economics. Available from: http://ideas.repec.org/p/cda/wpaper/12-24.html.

Kaufmann, Daniel, Aart Kraay and Massimo Mastruzzi (2010): "The worldwide governance indicators: methodology and analytical issues," Policy Research Working Paper No. 5430, The World Bank.

Kiss, Gergely and Gabor Vadas (2007): "The role of the housing market in monetary transmission - Evidence from Hungary," International Journal of Housing Policy, 7(3), 299-317.

Koop, Gary (2003): Bayesian Econometrics, Wiley.

Laeven, Luc and Fabian Valencia (2012): "Systemic Banking Crises: An Update," IMF Working Paper No. 12/163, International Monetary Fund.

Levin, Andrew, Chien-Fu Lin and Chia-Shang James Chu (2002): “Unit root tests in panel data: asymptotic and finite-sample properties," Journal of Econometrics, 108(1), 1-24.

Loayza, Norman V. and Romain Ranciere (2006): "Financial Development, Financial Fragility, and Growth," Journal of Money, Credit and Banking, 38(4), 1051-1076.

Lucas, Robert E. and Nancy L. Stokey (1987): "Money and interest in a cash-in-advance economy," Econometrica, 55(3), 491-513.

Madigan, David and Jeremy York (1995): “Bayesian Graphical Models for Discrete Data," International Statistical Review, 63(2), 215-232.

Melecky, Martin and Anca Maria Podpiera (2012): "Institutional structures of financial sector supervision, their drivers and emerging benchmark models," mimeo. Available from: http://mpra.ub.uni-muenchen. de/37059/1/MPRA_paper_37059.pdf.

Miller, Merton H. and Daniel Orr (1966): “A Model of the Demand for Money by Firms," The Quarterly Journal of Economics, 80(3), 413-435.

Mitchell-Innes, Alfred (1914): “The Credit Theory of Money," The Banking Law Journal, 31(Dec/Jan), 151168.

Pesaran, M. Hashem (1997): “The role of economic theory in modelling the long run," The Economic Journal, 107(440), 178-191.

Pesaran, M. Hashem, Yongcheol Shin and Ron P. Smith (1999): "Pooled mean group estimation of dynamic heterogeneous panels," Journal of the American Statistical Association, 94(446), 621-634.

Pesaran, M. Hashem and Ron P. Smith (1995): “Estimating long-run relationships from dynamic heterogeneous panels," Journal of Econometrics, 68(1), 79-113. 
Pétursson, Thórarinn G. (2000): “The representative household's demand for money in a cointegrated VAR model," Econometrics Journal, 3(2), 162-176.

Shimazaki, Hideaki and Shigeru Shinomoto (2007): "A method for selecting the bin size of a time histogram," Neural Computation, 19(6), 1503-1527.

(2010): "Kernel bandwidth optimization in spike rate estimation," Journal of Computational Neuroscience, 29(1), 171-182.

Sriram, Subramanian S. (2001): "A survey of recent empirical Money Demand Studies," IMF Staff Papers, 47(3), 334-365.

Taylor, John B. (1993): "Disretion versus policy rules in practice," Carnegie-Rochester Conference Series on Public Policy, 39(39), 195-214.

Tibshirani, Robert (1996): "Regression shrinkage and selection via the Lasso," Journal of the Royal Statistical Society, Series B, 58(1), 267-288.

Tobin, James (1956): "The Interest-Elasticity of Transactions Demand For Cash," The Review of Economics and Statistics, 38(3), 241-247.

(1969): "A general equilibrium approach to monetary theory," Journal of Money, Credit and Banking, 1(1), 15-29.

Werner, Richard (2011): "Economics as if banks mattered: A contribution based on the inductive methodology," The Manchester School, 79(Supplement S2), 25-35.

Zhao, Peng and Bin Yu (2006): “On model selection consistency of Lasso," Journal of Machine Learning Research, 7(2), 2541-2563.

Zou, H. (2006): "The adaptive lasso and its oracle properties," Journal of the American Statistical Association, 101(476), 1418-1429. 


\section{Tables and Figures}

Table 1: Mean Group estimation results

\begin{tabular}{|c|c|c|c|c|c|}
\hline Parameter on Variable: & Estimate & Std. error & $t$-statistic & $p$-value & $95 \% \mathrm{CI}$ \\
\hline GDP & $2.9613^{* * *}$ & 0.3260 & 9.0833 & 0.0000 & {$[2.3223,3.6002]$} \\
\hline GDP Deflator & 0.2744 & 0.3161 & 0.8681 & 0.1927 & {$[-0.3452,0.8940]$} \\
\hline Real interest rate & -0.0005 & 0.0090 & -0.0528 & 0.4790 & {$[-0.0181,0.0171]$} \\
\hline Lending to deposit spread & -0.0072 & 0.0120 & -0.5998 & 0.2743 & {$[-0.0308,0.0164]$} \\
\hline Alternative cost of borrowing & $-0.0029^{* *}$ & 0.0013 & -2.2184 & 0.0133 & {$[-0.0056,-0.0003]$} \\
\hline Error correction term & $-0.1631^{* * *}$ & 0.0235 & -6.9381 & 0.0000 & {$[-0.2092,-0.1170]$} \\
\hline Intercept term & $-1.8644^{* * *}$ & 0.2887 & -6.4573 & 0.0000 & {$[-2.4304,-1.2985]$} \\
\hline
\end{tabular}

Notes: This table shows the MG estimates of the long-run equilibrium parameters, and the error correction and the intercept terms in the top and bottom parts of the table, respectively. Estimates are computed as the arithmetic averages over the $N$ countries that are included in the estimation. Standard errors (Std. error) are computed as the sample standard deviation divided by $\sqrt{N}$ (see Pesaran and Smith, 1995 for more details). The column with the heading $p$-values reports one sided probability values under a standard normal distribution. The asterisks ${ }^{* * *},{ }^{* *}$, and ${ }^{*}$ denote significance at the $1 \%, 5 \%$, and $10 \%$ levels, respectively. The full estimation results for each country are available upon request. 
Table 2: Pooled Mean Group estimation results

\begin{tabular}{|c|c|c|c|c|c|}
\hline Parameter on Variable: & Estimate & Std. error & $t$-statistic & $p$-value & $95 \% \mathrm{CI}$ \\
\hline GDP (R) & $3.2672^{* * *}$ & 0.1201 & 27.2110 & 0.0000 & {$[3.0318,3.5026]$} \\
\hline GDP Deflator (R) & $0.2049^{* * *}$ & 0.0679 & 3.0170 & 0.0013 & $0.0718,0.3380]$ \\
\hline Real interest rate & $0.1488^{* * *}$ & 0.0408 & 3.6476 & 0.0001 & $0.0688,0.2288]$ \\
\hline Lending to deposit spread & $-0.3387^{* * *}$ & 0.0913 & -3.7110 & 0.0001 & {$[-0.5176,-0.1598]$} \\
\hline Alternative cost of borrowing & $-0.0140^{* *}$ & 0.0078 & -1.7986 & 0.0360 & {$[-0.0293,0.0013]$} \\
\hline Error correction term & $-0.0238^{* * *}$ & 0.0056 & -4.2416 & 0.0000 & {$[-0.0348,-0.0128]$} \\
\hline Intercept term & $-0.2424^{* * *}$ & 0.0554 & -4.3722 & 0.0000 & {$[-0.3510,-0.1338]$} \\
\hline Unrestricted log-likelihood: & 8359.71 & \multicolumn{3}{|c|}{ Restricted log-likelihood: } & 8089.54 \\
\hline
\end{tabular}

Notes: This table shows the PMG estimates of the long-run equilibrium parameters and the error correction and the intercept terms in the top and bottom parts of the table, respectively. Only the GDP and GDP Deflator parameters are restricted to be the same across the groups (countries). This is denoted by $(R)$ in the table above. All other parameters are left unrestricted. These estimates were computed using the system Maximum Likelihood Estimator of Pesaran et al. (1999). The column with the heading $p$-values reports one sided probability values under a standard normal distribution. The asterisks ${ }^{* * *},{ }^{* *}$, and * denote significance at the $1 \%, 5 \%$, and $10 \%$ levels, respectively. The full estimation results for each country are available upon request. 
Table 3: Posterior Inclusion Probabilities for $\hat{\beta}^{g d p}$ from BMA regressions

\begin{tabular}{|c|c|c|}
\hline Variable name & Description & PIP \\
\hline prudential1 & Integration of prudential supervision & 0.9953 \\
\hline cba_economic & Central bank economic independence & 0.9927 \\
\hline crisis & Financial crisis experience ( 0,1 dummy variable) & 0.9025 \\
\hline cba_political & Central bank political independence & 0.8675 \\
\hline s02cgp0 & Number of Branches per 100,000 Adults, Commercial Banks ${ }^{(1)}$ & 0.6809 \\
\hline s13ifs0 & Gross Portfolio Debt Assets/GDP (\%) & 0.6254 \\
\hline s01ifs0 & Private Credit/GDP (\%) & 0.6007 \\
\hline s14ifs0 & Gross Portfolio Equity Liabilities/GDP (\%) & 0.5603 \\
\hline eca & Europe and Central Asia (ECA) region dummy & 0.5363 \\
\hline s03bis0 & Outstanding International Private Debt Securities/GDP (\%) & 0.4549 \\
\hline s01ess0 & Percent of Firms With Line of Credit, All Firms (\%) & 0.3351 \\
\hline s12ifs0 & Gross Portfolio Equity Assets/GDP (\%) & 0.3045 \\
\hline $\mathrm{s} 01 \mathrm{wfe} 0$ & Percent Market Capitalization of Top 10 Largest Companies (\%) & 0.3026 \\
\hline s01wdi0 & Stock Market Turnover Ratio (\%) & 0.2980 \\
\hline s02fsio & Bank Capital to Assets (\%) & 0.2748 \\
\hline gdp_ppp & GDP per Capita PPP adjusted & 0.2712 \\
\hline s01axc0 & Insurance Premiums (Life)/GDP (\%) & 0.2637 \\
\hline s02bis0 & Outstanding Domestic Public Debt Securities/GDP (\%) & 0.2621 \\
\hline s01bis0 & Outstanding Domestic Private Debt Securities/GDP (\%) & 0.2609 \\
\hline governance1 & Kaufmann et al. (2010) overall governance indicator & 0.2577 \\
\hline s05wdi0 & Number of Listed Companies ${ }^{(1)}$ & 0.2196 \\
\hline s03ifs0 & Credit to Government and SOEs/GDP (\%) & 0.2191 \\
\hline s04fsio & Provisions to NPLs (\%) & 0.2150 \\
\hline s01fsio & Regulatory Capital to Risk-Weighted Assets (\%) & 0.1900 \\
\hline s05bis0 & Consolidated Foreign Claims of BIS-Reporting Banks/GDP (\%) & 0.1435 \\
\hline tradepgdp & Openness (imports plus exports over GDP) & 0.1390 \\
\hline s08bsk0 & 3 Bank Asset Concentration (\%) & 0.1318 \\
\hline s01_s03 & Private Credit/Number of Listed Companies (\%) & 0.1299 \\
\hline s06bsk0 & Return on Assets $(\%)$ & 0.1224 \\
\hline s10bsk0 & Liquid Assets / Deposits and Short Term Funding (\%) & 0.1119 \\
\hline s02ess0 & Percent of Firms With Line of Credit, Small Firms (\%) & 0.1112 \\
\hline s01nbf0 & Pension Fund Assets/GDP (\%) & 0.1078 \\
\hline s04bis0 & Outstanding International Public Debt Securities/GDP (\%) & 0.0924 \\
\hline s03bsk0 & Non-Interest Income / Total income (\%) & 0.0885 \\
\hline dist_crisis & Cumulative number of crises experienced by a country & 0.0144 \\
\hline s05bsk0 & Cost to Income Ratio (\%) & 0.0139 \\
\hline s09ifs0 & Private Credit to Deposits (\%) & 0.0132 \\
\hline s15ifs0 & Gross Portfolio Debt Liabilities/GDP (\%) & 0.0130 \\
\hline $\mathrm{s} 02 \mathrm{nbf} 0$ & Mutual Fund Assets/GDP (\%) & 0.0122 \\
\hline s07bsk0 & Return on Equity $(\%)$ & 0.0112 \\
\hline s03fsio & NPLs to Total Gross Loans (\%) & 0.0111 \\
\hline $\mathrm{s} 02 \mathrm{axc0}$ & Insurance Premiums (Non-Life)/GDP (\%) & 0.0020 \\
\hline
\end{tabular}

Notes: This table shows the Posterior inclusion probabilities (PIPs) of the 42 possible economic, financial and institutional development indicators for $\hat{\beta}^{g d p}$ computed from a Bayesian model averaging procedure, where a Zellner $\mathrm{g}$ - prior was used for the specification of the hyperparameter $\mathrm{g}$ in the variance prior of $\varphi^{g d p} \mid \sigma_{\epsilon}$. The $\mathrm{MC}^{3}$ algorithm of Madigan and York (1995) was used to generate draws from the model space. A chain with 75 million MCMC draws was run, where the first 25 million were discarded as a burn-in sample. The dashed line in the table above marks the cut off value at PIP $=25 \%$.

${ }^{(1)}$ denotes values that have been log transformed. 
Table 4: Lasso penalised regression estimates of $\phi^{g d p}$

\begin{tabular}{|c|c|c|}
\hline Variable name & Description & Lasso estimate of $\phi^{g d p}$ \\
\hline prudential1 & Integration of prudential supervision & 1.2064 \\
\hline cba_economic & Central bank economic independence & 4.5758 \\
\hline crisis & Financial crisis experience (0,1 dummy variable) & -1.4273 \\
\hline cba_political & Central bank political independence & 2.0995 \\
\hline s02cgp0 & Number of Branches per 100,000 Adults, Commercial Banks ${ }^{(1)}$ & -1.3186 \\
\hline s13ifs0 & Gross Portfolio Debt Assets/GDP (\%) & $\Rightarrow 0$ \\
\hline s01ifs0 & Private Credit/GDP (\%) & 0.0059 \\
\hline s14ifs0 & Gross Portfolio Equity Liabilities/GDP (\%) & $\Rightarrow 0$ \\
\hline eca & Europe and Central Asia (ECA) region dummy & 0.7137 \\
\hline s03bis0 & Outstanding International Private Debt Securities/GDP (\%) & $\Rightarrow 0$ \\
\hline s01ess0 & Percent of Firms With Line of Credit, All Firms (\%) & $\Rightarrow 0$ \\
\hline s12ifso & Gross Portfolio Equity Assets/GDP (\%) & $\Rightarrow 0$ \\
\hline s01wfe0 & Percent Market Capitalization of Top 10 Largest Companies (\%) & $\Rightarrow 0$ \\
\hline s01wdi0 & Stock Market Turnover Ratio (\%) & $\Rightarrow 0$ \\
\hline s02fsio & Bank Capital to Assets (\%) & $\Rightarrow 0$ \\
\hline gdp_ppp & GDP per Capita PPP adjusted & $\Rightarrow 0$ \\
\hline $\mathrm{s} 01 \mathrm{axc} 0$ & Insurance Premiums (Life)/GDP (\%) & $\Rightarrow 0$ \\
\hline s02bis0 & Outstanding Domestic Public Debt Securities/GDP (\%) & $\Rightarrow 0$ \\
\hline s01bis0 & Outstanding Domestic Private Debt Securities/GDP (\%) & $\Rightarrow 0$ \\
\hline governance1 & Kaufmann et al. (2010) overall governance indicator & $\Rightarrow 0$ \\
\hline
\end{tabular}

Notes: This table shows the Lasso penalised regression estimates of $\phi^{g d p}$. These were computed with a mean squared error (MSE) cross-validated complexity parameter $\lambda$. The symbol $\Rightarrow 0$ denotes coefficients that are shrunk towards zero by the Lasso estimator.

${ }^{(1)}$ denotes values that have been log transformed. 
Table 5: OLS cross-country regressions

\begin{tabular}{|c|c|c|c|}
\hline \multicolumn{2}{|r|}{ Explanatory Variables } & \multicolumn{2}{|c|}{ Dependent Variable } \\
\hline Variable name & Description of Variables & $\hat{\beta}^{g d p}$ & $\hat{\beta}^{\text {def }}$ \\
\hline $\begin{array}{l}\text { s01ifs } 0 \\
\text { (std. error) } \\
{[p-\text { value }]}\end{array}$ & Private Credit/GDP (\%) & $\begin{array}{l}0.0321^{* * *} \\
(0.0116) \\
{[0.0087]}\end{array}$ & - \\
\hline $\begin{array}{c}\text { s02cgp0 } \\
\text { (std. error) } \\
{[p \text {-value }]}\end{array}$ & Number of Branches per 100,000 Adults ${ }^{(1)}$ & $\begin{array}{c}-3.9798^{* * *} \\
(1.0599) \\
{[0.0005]}\end{array}$ & $\begin{array}{l}3.8461^{* * *} \\
(0.7451) \\
{[0.0000]}\end{array}$ \\
\hline $\begin{array}{c}\text { s05bsk0 } \\
\text { (std. error) } \\
\text { [p-value }]\end{array}$ & Cost to Income Ratio (\%) & - & $\begin{array}{l}0.1981^{* * * *} \\
(0.0627) \\
{[0.0031]}\end{array}$ \\
\hline $\begin{array}{l}\text { S01bis0 } \\
\text { (std. error) } \\
\text { [p-value }]\end{array}$ & Outstanding Domestic Private Debt Securities/GDP (\%) & - & $\begin{array}{c}-0.0353^{* * *} \\
(0.0110) \\
{[0.0034]}\end{array}$ \\
\hline $\begin{array}{c}\text { prudential1 } \\
\text { (std. error) } \\
{[p-\text { value }]}\end{array}$ & Integration of Prudential Supervision & $\begin{array}{l}1.5539^{* * *} \\
(0.4373) \\
{[0.0010]}\end{array}$ & $\begin{array}{c}-1.0809^{* * *} \\
(0.3731) \\
{[0.0060]}\end{array}$ \\
\hline $\begin{array}{l}\text { cba_political } \\
\text { (std. error) } \\
{[p-\text { value }]}\end{array}$ & Central Bank Political Independence & $\begin{array}{l}2.1719^{*} \\
(1.1178) \\
{[0.0589]}\end{array}$ & $\begin{array}{c}-4.8218^{* * *} \\
(1.1342) \\
{[0.0001]}\end{array}$ \\
\hline $\begin{array}{l}\text { cba_economic } \\
\text { (std. error) } \\
{[p-\text { value }]}\end{array}$ & Central Bank Economic Independence & $\begin{array}{l}6.6749^{* * *} \\
(2.0999) \\
{[0.0028]}\end{array}$ & $\begin{array}{c}-4.8525^{* *} \\
(1.8145) \\
{[0.0107]}\end{array}$ \\
\hline $\begin{array}{c}\text { crisis } \\
\text { (std. error) } \\
{[p-\text { value }]}\end{array}$ & Financial Crisis Experience (0,1 dummy variable) & $\begin{array}{c}-1.6136^{* *} \\
(0.7781) \\
{[0.0444]}\end{array}$ & $\begin{array}{l}2.6972^{* * *} \\
(0.6634) \\
{[0.0002]}\end{array}$ \\
\hline $\begin{array}{c}\text { eca } \\
\text { (std. error) } \\
\text { [p-value] }\end{array}$ & Europe and Central Asia (ECA) region dummy & $\begin{array}{c}1.0292 \\
(0.9379) \\
{[0.2789]}\end{array}$ & - \\
\hline \multirow[t]{7}{*}{$\begin{array}{c}\text { Constant } \\
\text { (std. error) } \\
{[p-\text { value }]}\end{array}$} & Intercept term & $\begin{array}{l}18.56^{* * *} \\
(6.1237) \\
{[0.0042]}\end{array}$ & $\begin{array}{c}-13.21^{* * *} \\
(4.3810) \\
{[0.004]}\end{array}$ \\
\hline & Log-Likelihood & -94.89 & -90.21 \\
\hline & Akaike Information Criterion (AIC) & 4.1999 & 4.0087 \\
\hline & Bayesian information criterion (BIC) & 4.5088 & 4.3176 \\
\hline & $\begin{array}{c}\text { R-squared } \\
\left\{\text { Adjusted } R^{2}\right\}\end{array}$ & $\begin{array}{l}0.4479 \\
\{0.3536\}\end{array}$ & $\begin{array}{l}0.5150 \\
\{0.4322\}\end{array}$ \\
\hline & $\frac{F-\text { statistic }}{[p-\text { value }]}$ & $\begin{array}{l}4.7518^{* * *} \\
{[0.0006]}\end{array}$ & $\begin{array}{l}6.2200^{* * *} \\
{[0.0001]}\end{array}$ \\
\hline & $\begin{array}{l}\text { BP Heteroskedasticity } \\
{[p-\text { value }]}\end{array}$ & $\begin{array}{c}5.8273 \\
{[0.5600]}\end{array}$ & $\begin{array}{l}9.2212 \\
{[0.2376]}\end{array}$ \\
\hline
\end{tabular}

Notes: This table shows the OLS regression estimates of the $\phi^{g d p}$ and $\phi^{\text {def }}$ parameters from the regressions of $\hat{\beta}^{g d p}$ and $\hat{\beta}^{\text {def }}$ on their respective relevant subset economic, financial and institutional development indicators selected from the BMA and Lasso procedures. Standard errors (denoted by std. error in parenthesis below estimates) are homoskedastic standard errors. Two sided probability values (denoted by $p$-value) are reported in square brackets below the estimates and the standard errors. Values in the bottom part of the table show standard regression goodness-of-fit and mis-specification indicators. The entry next to BP Heteroskedasticity is the Breusch-Pagan test for heteroskedasticity. The asterisks ${ }^{* * *}$, ${ }^{* *}$, and ${ }^{*}$ denote significance at the $1 \%, 5 \%$, and $10 \%$ levels, respectively.

(1) denotes values that have been log transformed. 


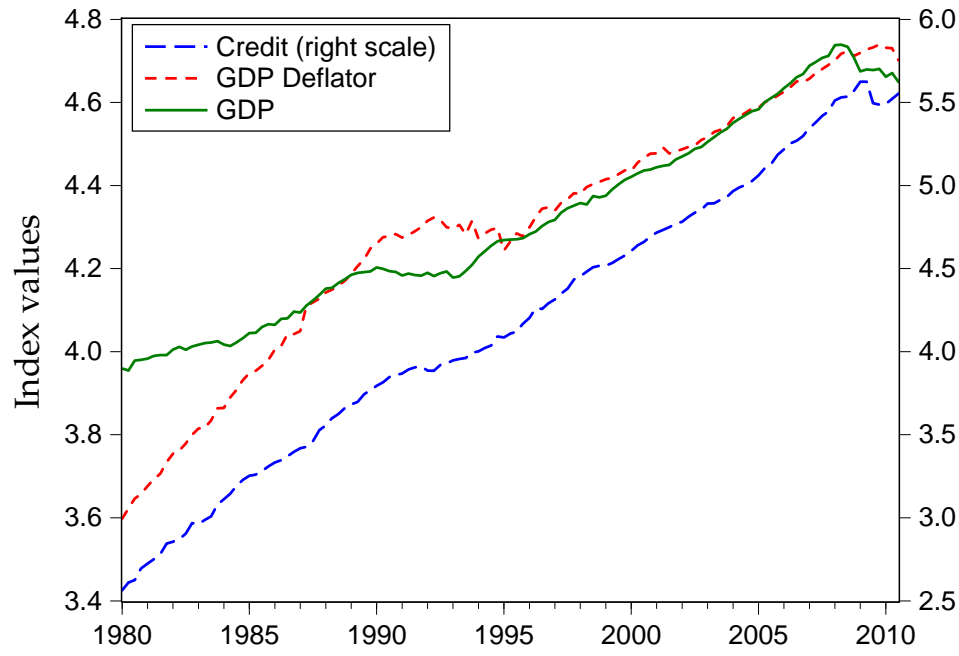

(a) Levels

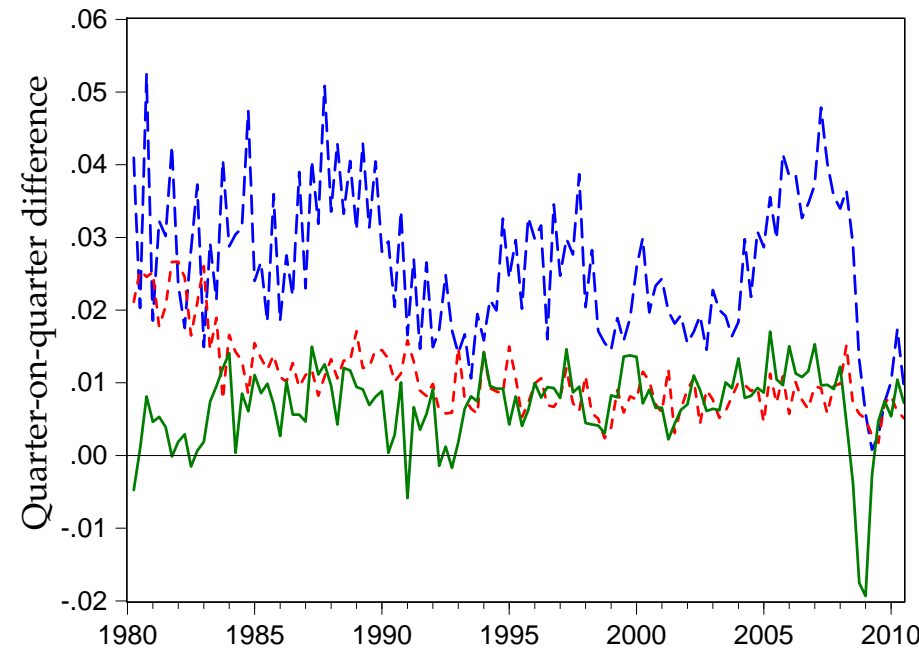

(b) Growth rates (quarter-on-quarter)

Figure 1: Time series evolution of the cross-country averages (medians) of our three main macroeconomic variables. The dashed (blue) line shows credit (right scale), the short-dashed (red) line shows the GDP Deflator, and the solid (green) line shows GDP. Panel (a) plots the levels of the series. Panel (b) shows the corresponding quarter-on-quarter growth rates (first differences).

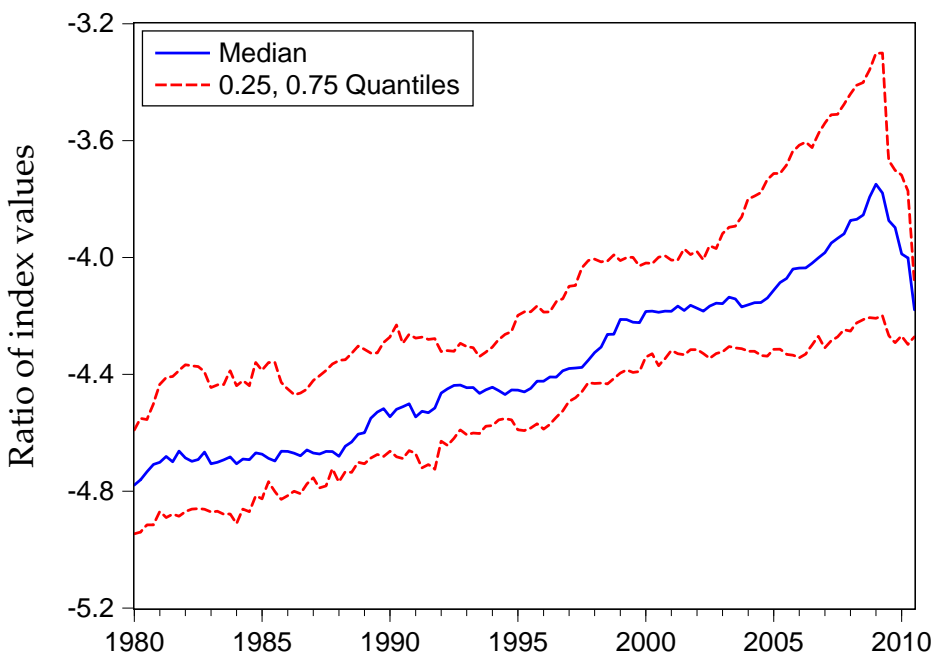

(a) Levels

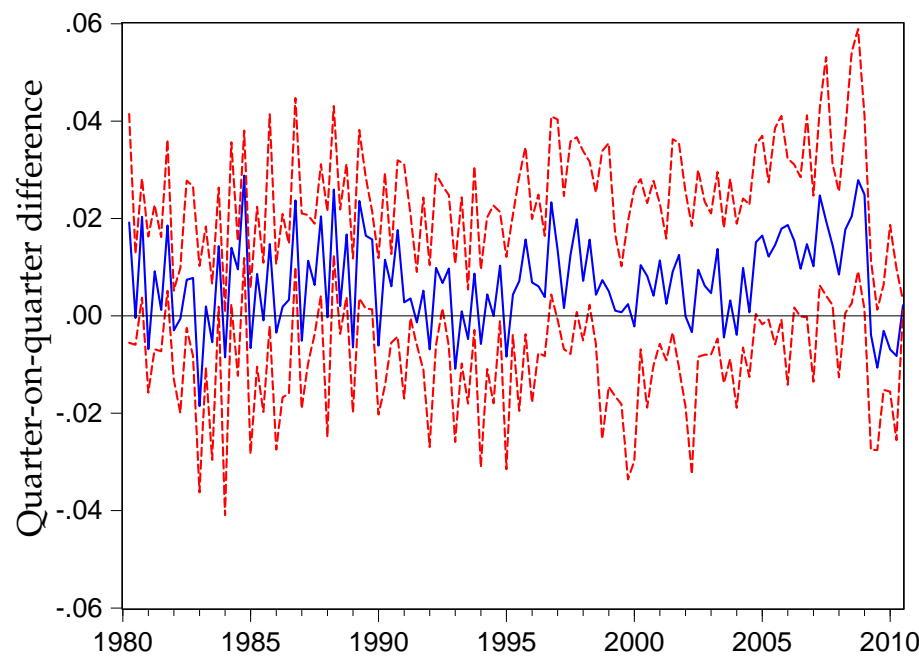

(b) Growth rates (quarter-on-quarter)

Figure 2: Time series evolution of the cross-country averages (medians) of the credit-to-GDP ratio. The solid (blue) line shows the median of the credit-to-GDP ratio and the dashed (red) lines show the corresponding $25^{\text {th }}$ and $75^{\text {th }}$ cross-sectional quantiles. Panel (a) plots the levels of the series. Panel (b) shows the corresponding quarter-on-quarter growth rates (first differences). 


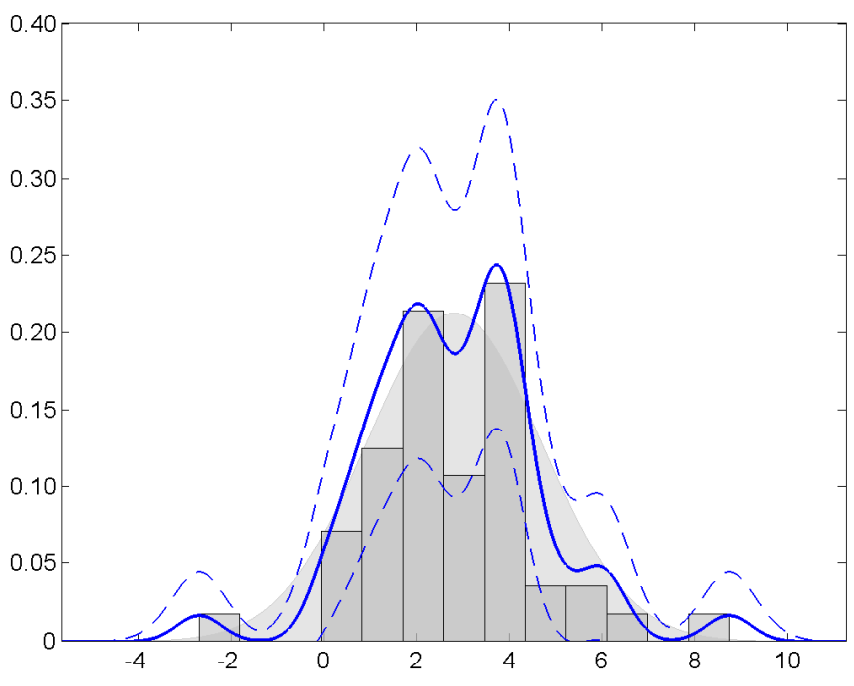

(a) Distribution of $\hat{\beta}^{g d p}$

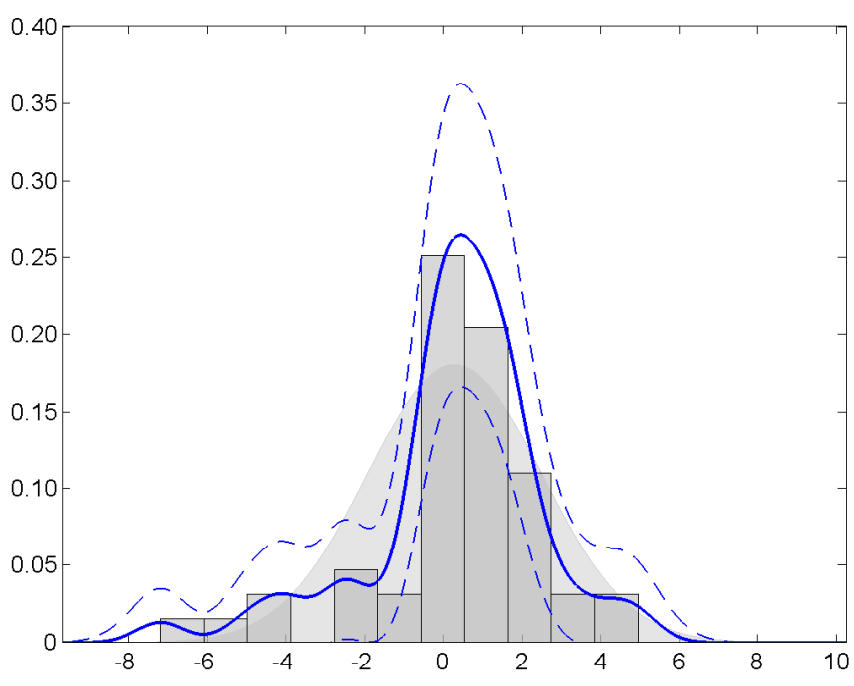

(b) Distribution of $\hat{\beta}^{\text {def }}$

Figure 3: Histograms and density estimates of the $\hat{\beta}^{g d p}$ and $\hat{\beta}^{\text {def }}$ coefficients. Corresponding 95\% (asymptotic) confidence intervals are denoted by the (blue) dashed line. A normal density, centered and scaled at the sample mean and standard deviation, is plotted in light gray in the background. Optimal smoothing bandwidth and histogram bin size were selected using the approaches of Shimazaki and Shinomoto $(2010,2007)$, respectively. 


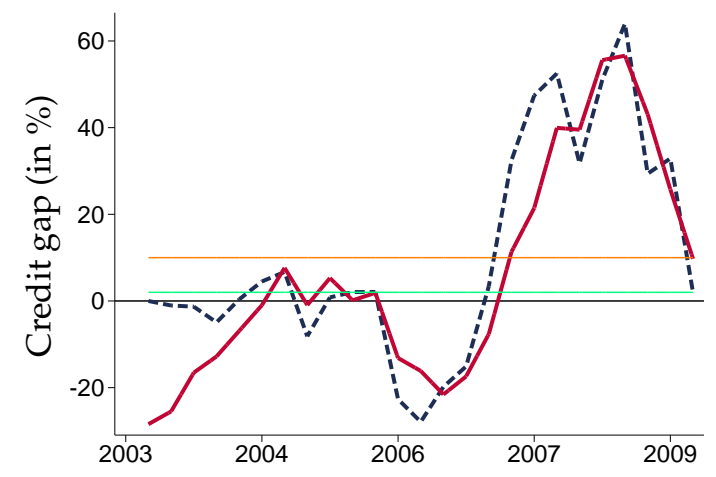

(a) Bulgaria (Crisis: 96 - 97)

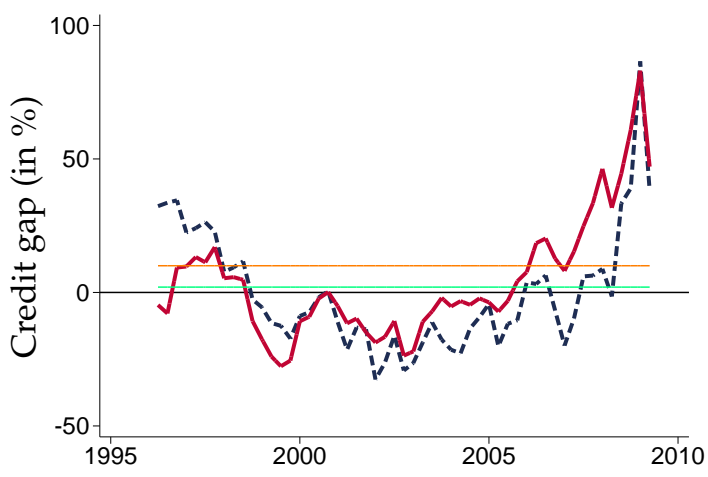

(d) Hungary (Crisis: $91-95,08-$ )

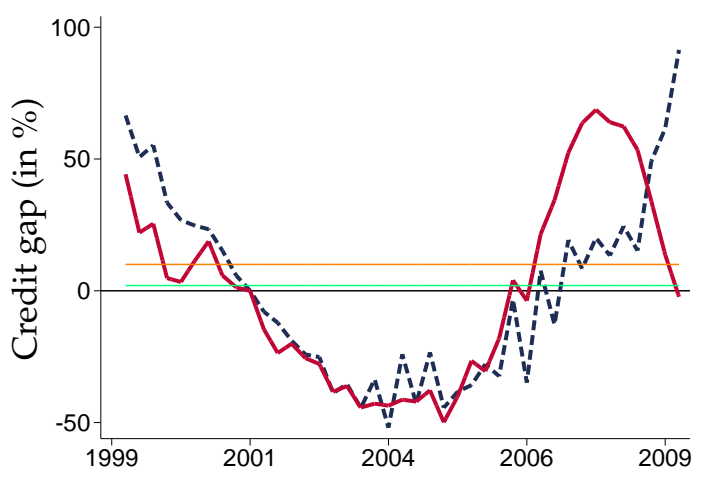

(g) Estonia (Crisis: 92 - 94)

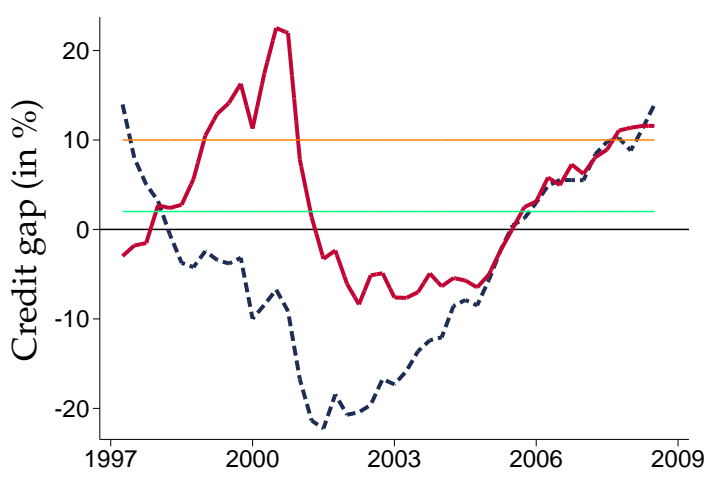

(j) Slovak Republic (Crisis: 98 - 02)

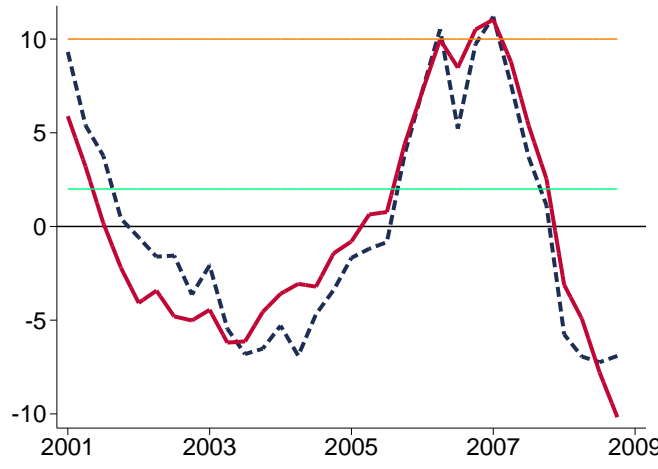

(b) Czech Republic (Crisis: 96 - 00)

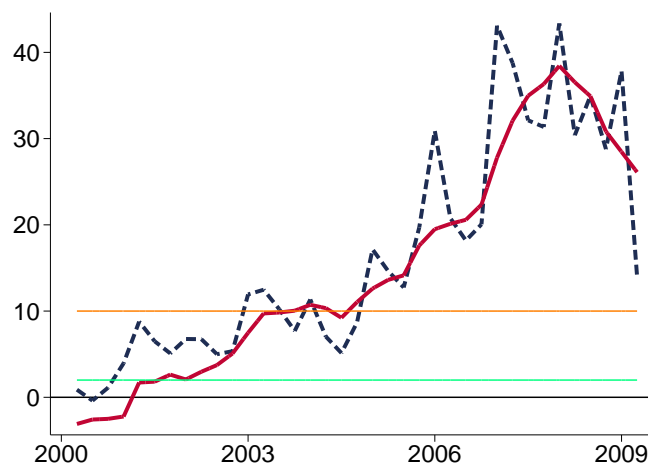

(e) Romania (Crisis: 90 - 92)

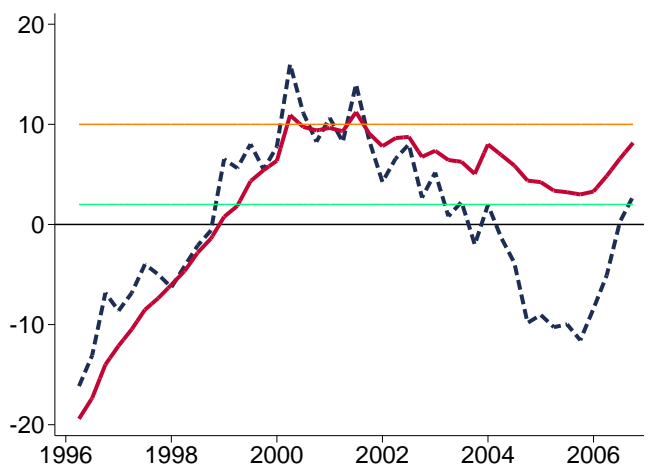

(h) Poland (Crisis: $92-94$ )

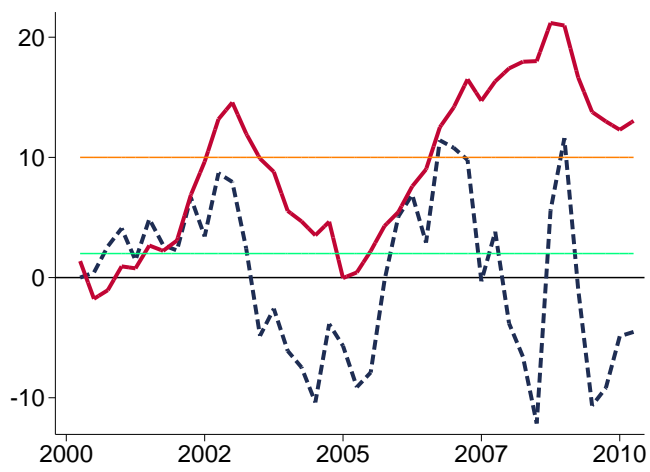

(k) Croatia (Crisis: 98 - 99)

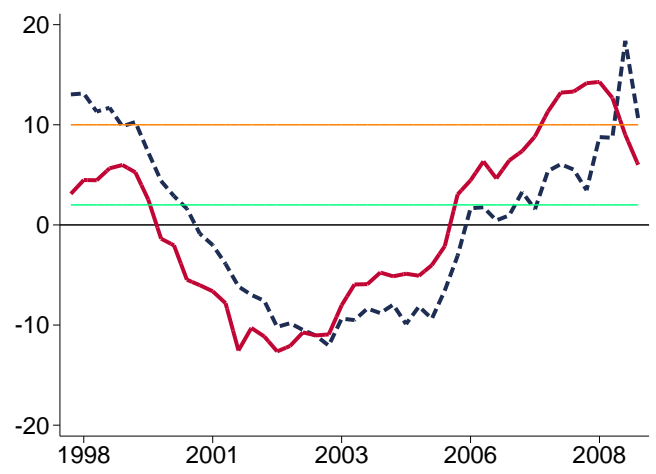

(c) Lithuania (Crisis: 95 - 96)

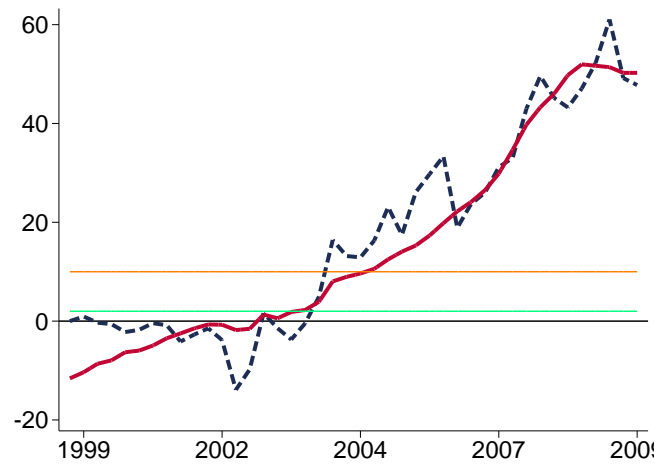

(f) Slovenia (Crisis: 92, 08-)

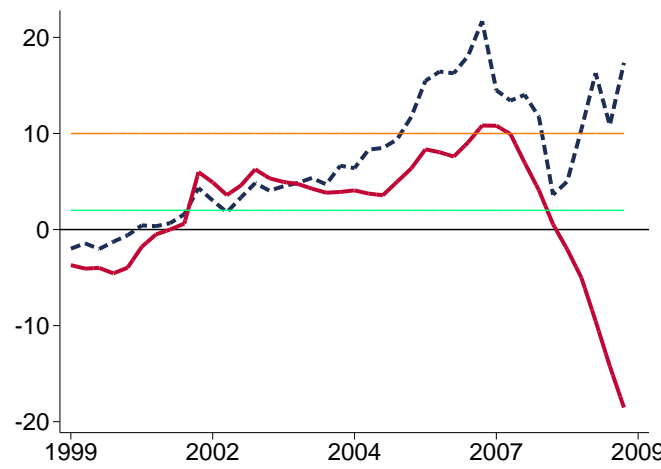

(i) Latvia (Crisis: 95 - 96, 08-)

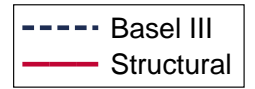

Figure 4: Comparison of estimates of credit gaps (excessive/lacking credit provision). The dashed (blue) line shows the Basel III HP-filter based measure of excessive credit. The solid (red) line shows our proposed structural credit gap. The two (orange and green) vertical lines show the $2 \%$ and $10 \%$ thresholds of the Basel III regulatory framework that triggers the capital buffer add-on. "Crisis" refers to banking crisis as classified according to the Laeven and Valencia (2012) database. 


\section{Appendix for:}

\section{"Equilibrium Credit: The Reference Point for Macroprudential Supervisors"}

This appendix provides additional estimation results and robustness checks to complement the results that are presented in the main part of the paper.

\section{A. Cross-country distribution of the remaining long-run equilibrium parameters}

Histograms and density estimates of remaining long-run equilibrium parameters of the relation in (6) are shown in Figure A.1 below.

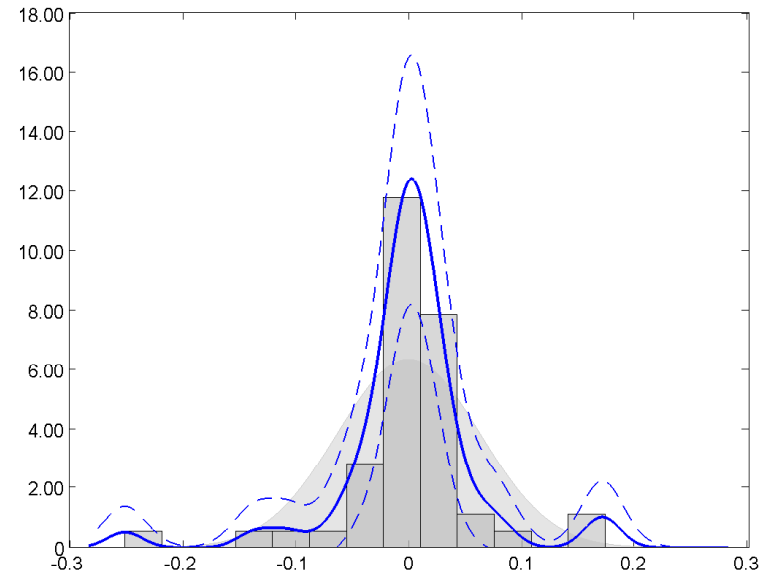

(a) Distribution of $\hat{\beta}^{r r}$

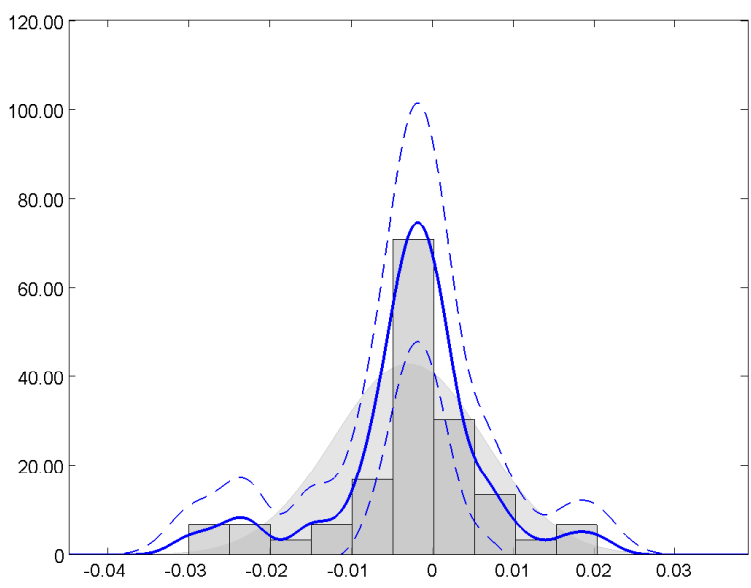

(c) Distribution of $\hat{\beta}^{a c b}$

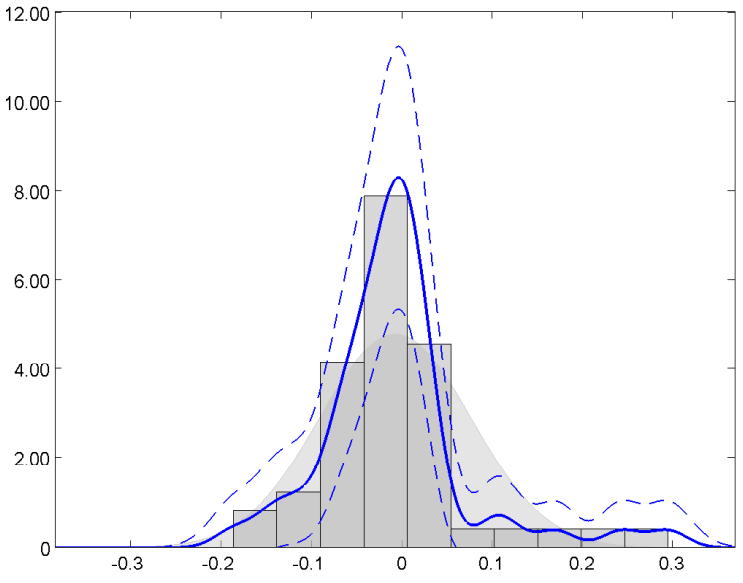

(b) Distribution of $\hat{\beta}^{\text {sprd }}$

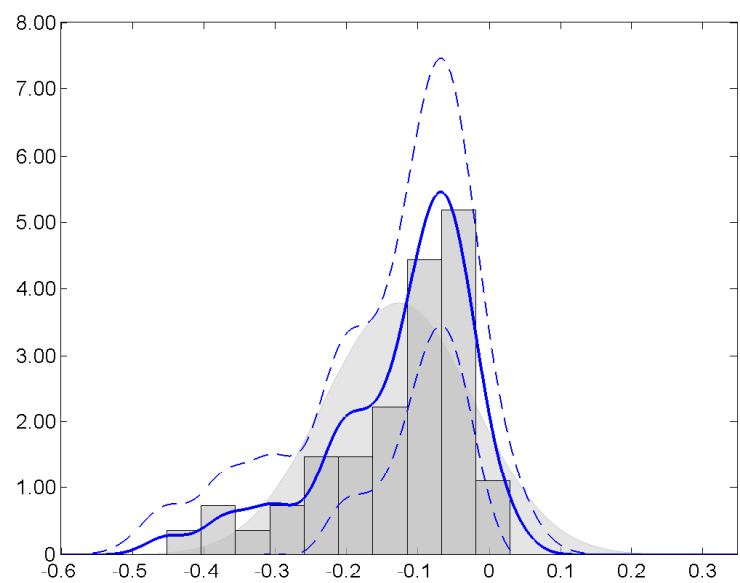

(d) Distribution of $\hat{\alpha}$

Figure A.1: Histograms and density estimates of $\hat{\beta}^{r r}, \hat{\beta}^{\text {sprd }}$ and $\hat{\beta}^{a c b}$ and $\hat{\alpha} .95 \%$ (asymptotic) confidence intervals are denoted by the (blue) dashed line. A normal density, centered and scaled at the sample mean and standard deviation, is plotted in light gray in the background. Optimal smoothing bandwidth and histogram bin size were selected using the approaches of Shimazaki and Shinomoto $(2010,2007)$, respectively.

The distributions of the $\hat{\beta}^{r r}, \hat{\beta}^{\text {sprd }}$ and $\hat{\beta}^{a c b}$ coefficients that are part of the credit velocity equation in (5) are displayed in Panels (a), (b) and (c) of Figure A.1. Recall that we are not per se interested in the distributions of these coefficients and show them only for completeness and to contrast them with the bimodality seen in $\hat{\beta}^{g d p}$. Overall, these three distributions look uni-modal, with the peaks of the densities centered at values marginally below zero. This suggests that, on average, credit responds negatively to 
increasing values in the lending to deposit rate spread, the real interest rate, as well as the alternative cost of borrowing in foreign currency, when measured at the mode.

These three distributions show also some sizable variability around the zero line, which is an indication that the population parameters corresponding to the aggregate coefficients are most likely not significantly different from zero. Notice here also that although the distributions do not look Bell-shaped, they are reasonably symmetric. The $\hat{\beta}^{r r}$ coefficients show signs of fat tails with a high peak at around zero. The $\hat{\beta}^{\text {sprd }}$ coefficients, on the other hand, are somewhat positively skewed. Finally, the $\hat{\beta}^{a c b}$ coefficients portray a higher than expected frequency of values within the -0.03 to -0.02 interval, indicated by the mild bump in the far left tail of Panel (c).

The distribution of the speed of adjustment coefficients $\hat{\alpha}$ displayed in Panel (d) of Figure A.1 show less evidence of bi-modality, but a decisive left skew. Skewness in a distribution can come from a variety of sources. If one interprets the left skew as arising from a mixture of three distributions, then one may argue that three modes are visible at values in the -0.10 and -0.05 interval (the main mode), as well as at -0.20 and -0.30 . This seems to indicate that some heterogeneity exists in how fast deviations from long-run equilibrium credit are eliminated. A handful of countries have large (in absolute value) estimates of the speed of adjustment parameter, with some being around - or in excess of -0.4 .

\section{B. BMA and Lasso results for GDP Deflator}

The results of the BMA regression follow the same structure as those provided in the paper for the selection of the relevant variables for $\hat{\beta}^{g d p}$. Table B.1 below shows the posterior inclusion probabilities of the development indicators for the $\hat{\beta}^{\text {def }}$ BMA "regression".

The corresponding Lasso penalised regression estimates are shown below in Table B.2. We again use the notation $\Rightarrow$ to denote that a coefficient was shrunk to zero. Both of these results are provided for completeness purposes and are presented without any discussion. 
Table B.1: Posterior Inclusion Probabilities for $\hat{\beta}^{\text {def }}$ from BMA regressions

\begin{tabular}{|c|c|c|}
\hline Variable name & Description & PIP \\
\hline crisis & Financial crisis experience ( 0,1 dummy variable) & 0.9974 \\
\hline cba_political & Central bank political independence & 0.9967 \\
\hline prudential1 & Integration of prudential supervision & 0.9071 \\
\hline s02cgp0 & Number of Branches per 100,000 Adults, Commercial Banks ${ }^{(1)}$ & 0.6100 \\
\hline s07bsk0 & Return on Equity $(\%)$ & 0.5881 \\
\hline s01bis0 & Outstanding Domestic Private Debt Securities/GDP (\%) & 0.5684 \\
\hline s14ifs0 & Gross Portfolio Equity Liabilities/GDP (\%) & 0.4715 \\
\hline s03bsk0 & Non-Interest Income / Total income (\%) & 0.4406 \\
\hline cba_economic & Central bank economic independence & 0.4148 \\
\hline eca & Europe and Central Asia (ECA) region dummy & 0.3301 \\
\hline s13ifso & Gross Portfolio Debt Assets/GDP (\%) & 0.3147 \\
\hline s15ifs0 & Gross Portfolio Debt Liabilities/GDP (\%) & 0.3112 \\
\hline s12ifs0 & Gross Portfolio Equity Assets/GDP (\%) & 0.3074 \\
\hline s01ifs0 & Private Credit/GDP (\%) & 0.3046 \\
\hline s03bis0 & Outstanding International Private Debt Securities/GDP & 0.2811 \\
\hline s03ifs0 & Credit to Government and SOEs/GDP (\%) & 0.2799 \\
\hline s05bsk0 & Cost to Income Ratio (\%) & 0.2767 \\
\hline s09ifs0 & Private Credit to Deposits (\%) & 0.2573 \\
\hline s02bis0 & Outstanding Domestic Public Debt Securities/GDP (\%) & 0.2524 \\
\hline s01axc0 & Insurance Premiums (Life)/GDP (\%) & 0.2494 \\
\hline gdp_ppp & GDP per Capita PPP adjusted & 0.2473 \\
\hline s01ess0 & Percent of Firms With Line of Credit, All Firms (\%) & 0.2397 \\
\hline s05bis0 & Consolidated Foreign Claims of BIS-Reporting Banks/GDP(\%) & 0.2035 \\
\hline s02ess0 & Percent of Firms With Line of Credit, Small Firms (\%) & 0.1813 \\
\hline s01fsio & Regulatory Capital to Risk-Weighted Assets (\%) & 0.1261 \\
\hline s01wdi0 & Stock Market Turnover Ratio (\%) & 0.1221 \\
\hline s04bis0 & Outstanding International Public Debt Securities/GDP (\%) & 0.1158 \\
\hline s04fsio & Provisions to NPLs (\%) & 0.1042 \\
\hline s05wdi0 & Number of Listed Companies ${ }^{(1)}$ & 0.1027 \\
\hline s02fsio & Bank Capital to Assets (\%) & 0.1016 \\
\hline dist_crisis & Cumulative number of crises experienced by a country & 0.1011 \\
\hline $\mathrm{s} 02 \mathrm{axc0}$ & Insurance Premiums (Non-Life)/GDP (\%) & 0.0987 \\
\hline s03fsio & NPLs to Total Gross Loans (\%) & 0.0980 \\
\hline s02nbfo & Mutual Fund Assets/GDP (\%) & 0.0974 \\
\hline s06bsk0 & Return on Assets $(\%)$ & 0.0963 \\
\hline s08bsk0 & 3 Bank Asset Concentration (\%) & 0.0889 \\
\hline s01wfe0 & Percent Market Capitalization of Top 10 Largest Companies (\%) & 0.0887 \\
\hline s01_s03 & Private Credit/Number of Listed Companies (\%) & 0.0812 \\
\hline s10bsk0 & Liquid Assets / Deposits and Short Term Funding (\%) & 0.0757 \\
\hline s01nbf0 & Pension Fund Assets/GDP (\%) & 0.0751 \\
\hline governance1 & Kaufmann et al. (2010) overall governance indicator & 0.0646 \\
\hline tradepgdp & Openness (imports plus exports over GDP) & 0.0606 \\
\hline
\end{tabular}

Notes: This table shows the Posterior inclusion probabilities (PIPs) of the 42 possible economic, financial and institutional development indicators for $\hat{\beta}^{\text {def }}$ computed from a Bayesian Model Averaging procedure, where a Zellner g-prior was used for the specification of the hyperparameter $g$ in the variance prior of $\varphi^{d e f} \mid \sigma_{\epsilon}$. The $M C^{3}$ algorithm of Madigan and York (1995) was used to generate draws from the model space. A chain with 75 million MCMC draws was run, where the first 25 million were discarded as a burn-in sample. The dashed line in the table above marks the cut off value at PIP $=25 \%$.

(1) denotes values that have been log transformed. 
Table B.2: Lasso penalised regression estimates of $\phi^{\text {def }}$

\begin{tabular}{|c|c|c|}
\hline Variable name & Description & Lasso estimate of $\phi^{\text {def }}$ \\
\hline crisis & Financial crisis experience $(0,1$ dummy variable) & 2.1993 \\
\hline cba_political & Central bank political independence & -3.2696 \\
\hline prudential1 & Integration of prudential supervision & -1.0071 \\
\hline s01bis0 & Outstanding Domestic Private Debt Securities / GDP (\%) & -0.0495 \\
\hline s03bsk0 & Non-Interest Income / Total income (\%) & $\Rightarrow 0$ \\
\hline cba_economic & Central bank economic independence & -3.6348 \\
\hline s02cgp0 & Number of Branches per 100,000 Adults, Commercial Banks ${ }^{(1)}$ & 1.9805 \\
\hline s07bsk0 & Return on Equity $(\%)$ & $\Rightarrow 0$ \\
\hline s14ifs0 & Gross Portfolio Equity Liabilities / GDP (\%) & $\Rightarrow 0$ \\
\hline eca & Europe and Central Asia (ECA) region dummy & $\Rightarrow 0$ \\
\hline s13ifs0 & Gross Portfolio Debt Assets / GDP (\%) & $\Rightarrow 0$ \\
\hline s15ifs0 & Gross Portfolio Debt Liabilities / GDP (\%) & $\Rightarrow 0$ \\
\hline s12ifso & Gross Portfolio Equity Assets / GDP (\%) & $\Rightarrow 0$ \\
\hline s01ifs0 & Private Credit / GDP $(\%)$ & $\Rightarrow 0$ \\
\hline s03bis0 & Outstanding International Private Debt Securities / GDP (\%) & $\Rightarrow 0$ \\
\hline s03ifs0 & Credit to Government and SOEs / GDP (\%) & $\Rightarrow 0$ \\
\hline s05bsk0 & Cost to Income Ratio (\%) & 0.0884 \\
\hline s09ifs0 & Private Credit to Deposits (\%) & $\Rightarrow 0$ \\
\hline s02bis0 & Outstanding Domestic Public Debt Securities / GDP (\%) & $\Rightarrow 0$ \\
\hline s01axc0 & Insurance Premiums (Life) / GDP (\%) & $\Rightarrow 0$ \\
\hline gdp_ppp & GDP per Capita PPP adjusted & $\Rightarrow 0$ \\
\hline
\end{tabular}

Notes: This table shows the Lasso penalised regression estimates of $\phi^{\text {def }}$. These were computed with a mean squared error (MSE) cross-validated complexity parameter $\lambda$. The symbol $\Rightarrow 0$ denotes coefficients that are shrunk towards zero by the Lasso estimator.

(1) denotes values that have been log transformed. 


\section{Additional cross-sectional model fit results}

In addition to the overview of the model fits of the regressions reported in Table 5 , we provide here extra graphical evidence of how well the models fit the $\hat{\beta}^{\text {gdp }}$ and $\hat{\beta}^{\text {def }}$ coefficients. The top and bottom Panels of Figure C.2 show the actual as well as fitted values of the regressions. Both models track the actual series quite well, with a reasonably good ability to fit countries that are away from the general centre of the series (see, for example, the fits for Finland, Mexico and Georgia for the $\hat{\beta}^{g d p}$ series and the fits for Finland and the Czech Republic for the $\hat{\beta}^{\text {def }}$ series). A mildly worse fit is obtained for some of the countries plotted on the right hand side of the Panels in Figure C.2. For the $\hat{\beta}^{\text {def }}$ series, this concerns Poland, Romania, Georgia and Thailand. For the $\hat{\beta}^{\text {gdp }}$ series, this concerns Israel, Egypt and South Korea.

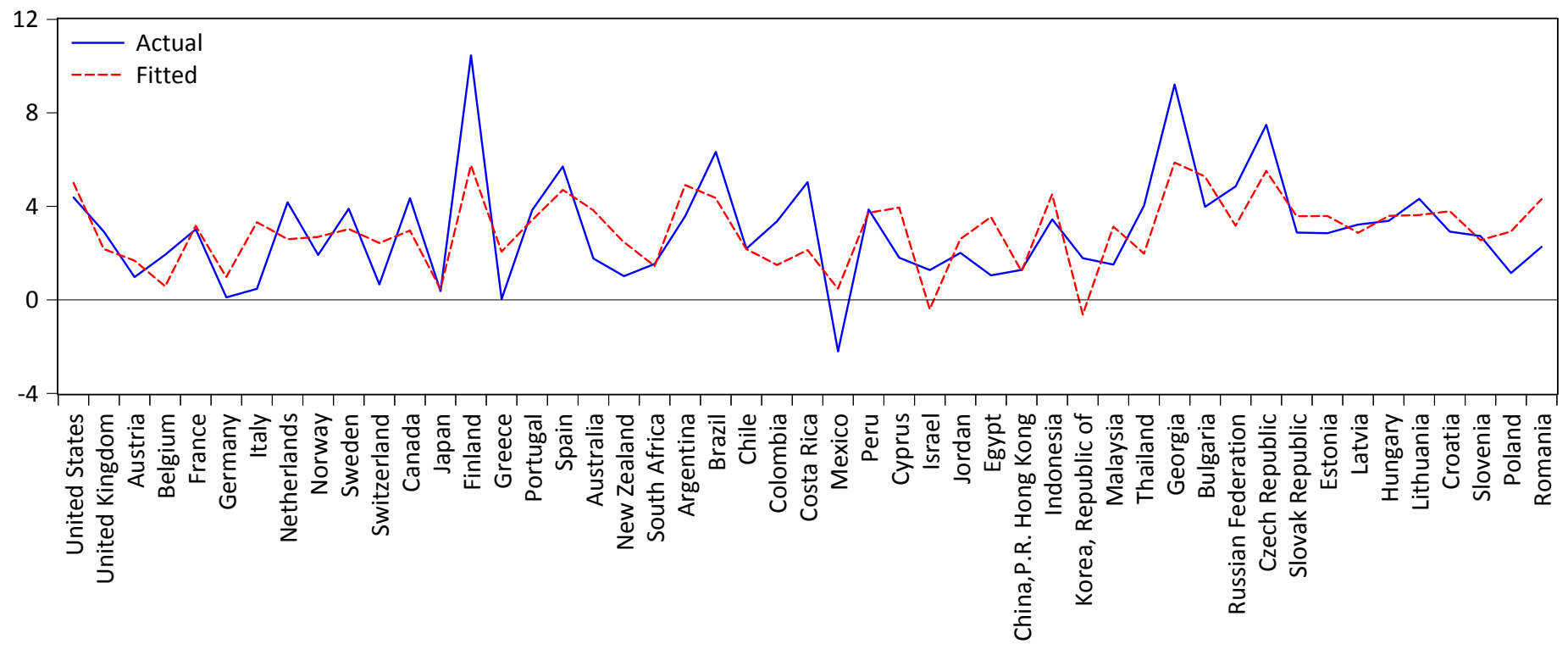

(a) Actual and fitted values of $\hat{\beta}^{d p}$

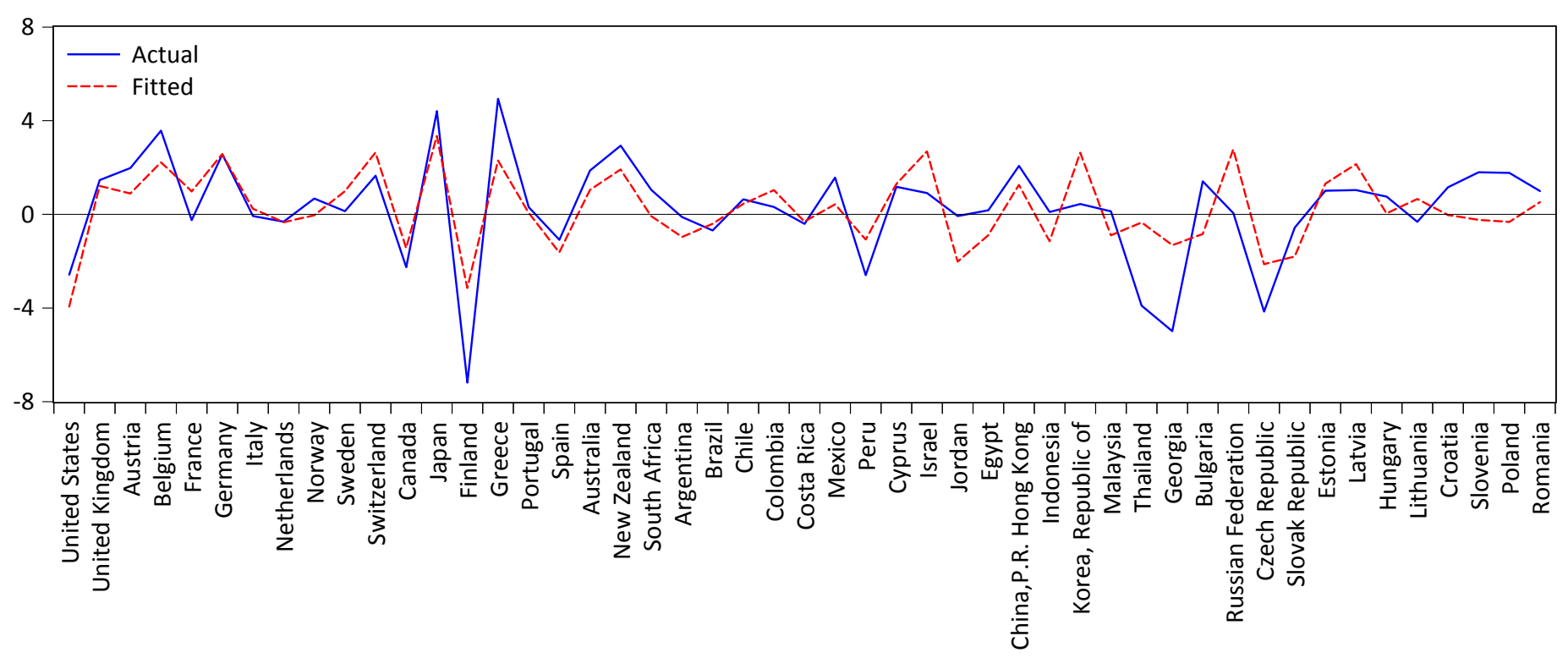

(b) Actual and fitted values of $\hat{\beta}^{\text {def }}$

Figure C.2: This figure shows the actual (blue solid line) and fitted (dashed red line) values of $\hat{\beta}^{\text {gdp }}$ and $\hat{\beta}^{\text {def }}$ from the regressions on their respective relevant subset economic, financial and institutional development indicators as reported in Table 5. The cross-countries that are included in the regressions are shown on the $x$-axis labels of the plots. 
We also investigate the distributional properties of the $\hat{\beta}^{g d p}$ and $\hat{\beta}^{\text {def }}$ regression residuals. Similar to the set-up in Section 4.1, we produce histogram and density plots of the regression residuals. These are shown in Figure C.3. Panel (a) of Figure C.3 shows the residuals from the $\hat{\beta}^{g d p}$ regression. The bi-modality in the distribution of the $\hat{\beta}^{g d p}$ coefficient disappears and the distribution takes on a more Normal looking shape once we condition on the relevant subset cross-country development indicators for $\hat{\beta}^{g d p}$. The skewness and kurtosis values are 0.1573 and 2.8265, respectively, yielding a Jarque-Bera test statistic of 0.2582 , with a corresponding Monte Carlo simulated $p$-value in excess of $0.50 .^{\text {A.1 }}$ The Jarque-Bera test for Normality thus fails to reject the null hypothesis of the data matching the skewness and kurtosis of a Normal distribution. ${ }^{\text {A.2 }}$

The plot in Panel (b) of Figure C.3 shows the empirical distribution of the residuals from the crosscountry regression of $\hat{\beta}^{\text {def }}$ on its relevant indicators. Recall that the distribution of $\hat{\beta}^{\text {def }}$ plotted in Panel (c) of Figure 3 showed signs of substantial kurtosis and mild skewness. By conditioning the $\hat{\beta}^{\text {def }}$ coefficient on its relevant development indicators, the kurtosis and also the skewness in the distribution are noticeably reduced. Skewness and kurtosis values are now -0.5204 and 3.6797, respectively, yielding a Jarque-Bera test statistic of 3.0904, with a corresponding Monte Carlo simulated $p$-value of 0.1032 . The statistical evidence in favour of the $\hat{\beta}^{\text {def }}$ regression residuals being Normally distributed is thus somewhat weaker than for the $\hat{\beta}^{g d p}$ regression residuals, nevertheless, there are no evident signs of strong departures from Normality.

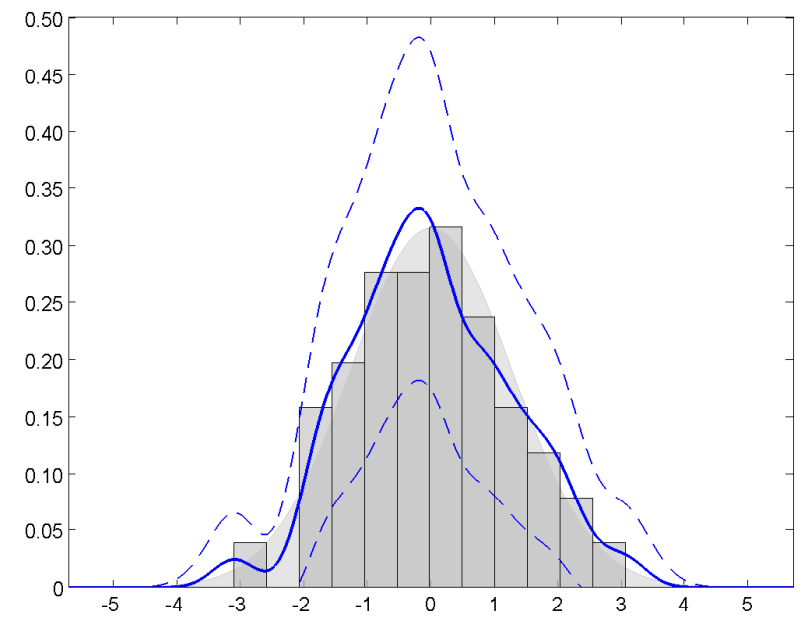

(a) Distribution of $\hat{\beta}^{g d p}$ residuals

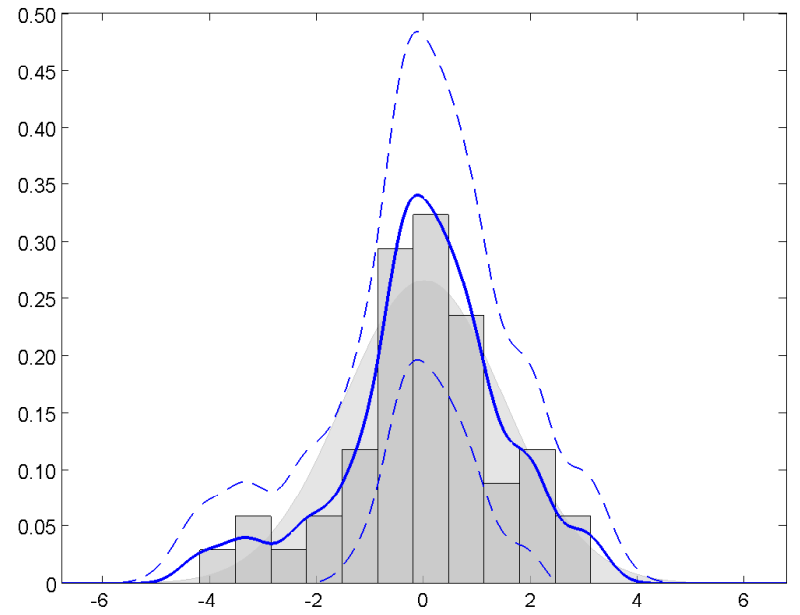

(b) Distribution of $\hat{\beta}^{\text {def }}$ residuals

Figure C.3: Histograms and density estimates of the residuals from the $\hat{\beta}^{g d p}$ and $\hat{\beta}^{\text {def }}$ regressions on their respective relevant subset economic, financial and institutional development indicators as reported in Table 5. 95\% (asymptotic) confidence intervals are denoted by the (blue) dashed line. A normal density is plotted in light gray in the background. Optimal smoothing bandwidth and histogram bin size were selected using the approaches of Shimazaki and Shinomoto $(2010,2007)$, respectively.

\section{Robustness check of cross-sectional regression}

As a robustness check to the regressions that are reported in Table 5 of the individually selected subset of relevant regression indicators for $\hat{\beta}^{g d p}$ and $\hat{\beta}^{d e f}$, we show regression results for the union of the individually selected indicators for both dependent variables in Table D.3. That is, the explanatory regressor variables are kept the same for the two regressions with $\hat{\beta}^{g d p}$ and $\hat{\beta}^{d e f}$ as the dependent variables, where this set is made up as the union of the individually selected regressors form the BMA and Lasso procedures.

\footnotetext{
A.1 We use the Matlab function jbtest which relies on Monte Carlo simulation to compute the $p$-values of the JarqueBera test, due to the well known oversensitivity of the asymptotic Chi-squared approximation in small samples.

A.2 This is evidently a weak test of Normality as it only tests the $3^{\text {rd }}$ and $4^{\text {th }}$ moments of a series. Nonetheless, the intention here is solely to provide some indication that the distribution of the residuals is much better behaved in terms of shape than the original distribution of the $\hat{\beta}^{g d p}$ series.
} 
Table D.3: OLS cross-country regressions

\begin{tabular}{|c|c|c|c|}
\hline \multicolumn{2}{|r|}{ Explanatory Variables } & \multicolumn{2}{|c|}{ Dependent Variable } \\
\hline Variable name & Description of Variables & $\hat{\beta}^{g d p}$ & $\hat{\beta}^{d e f}$ \\
\hline $\begin{array}{c}\text { s01ifs } 0 \\
\text { (std. error) } \\
\text { [p-value] }\end{array}$ & Private Credit/GDP (\%) & $\begin{array}{c}0.0243 \\
(0.0145) \\
{[0.1030]}\end{array}$ & $\begin{array}{c}-0.0066 \\
(0.0131) \\
{[0.6178]}\end{array}$ \\
\hline $\begin{array}{l}\text { s02cgp0 } \\
\text { (std. error) } \\
\text { [p-value }]\end{array}$ & Number of Branches per 100,000 Adults ${ }^{(1)}$ & $\begin{array}{c}-3.7675^{* * *} \\
(1.1402) \\
{[0.0020]}\end{array}$ & $\begin{array}{l}4.6825^{* * *} \\
(1.5090) \\
{[0.0036]}\end{array}$ \\
\hline $\begin{array}{c}\text { s05bsk0 } \\
\text { (std. error) } \\
\text { [p-value] }\end{array}$ & Cost to Income Ratio (\%) & $\begin{array}{c}-0.0351 \\
(0.0804) \\
{[0.6649]}\end{array}$ & $\begin{array}{l}0.1775^{\text {*** }} \\
(0.0705) \\
{[0.0160]}\end{array}$ \\
\hline $\begin{array}{l}\text { s01bis0 } \\
\text { (std. error) } \\
\text { [p-value] }\end{array}$ & Outstanding Domestic Private Debt Securities/GDP (\%) & $\begin{array}{c}0.0173 \\
(0.0145) \\
{[0.2421]}\end{array}$ & $\begin{array}{c}-0.0372^{* * *} \\
(0.0134) \\
{[0.0082]}\end{array}$ \\
\hline $\begin{array}{c}\text { prudential1 } \\
\text { (std. error) } \\
{[p-\text { value }]}\end{array}$ & Integration of Prudential Supervision & $\begin{array}{l}1.5212^{* * *} \\
(0.4412) \\
{[0.0014]}\end{array}$ & $\begin{array}{c}-1.0709^{* * *} \\
(0.3914) \\
{[0.0093]}\end{array}$ \\
\hline $\begin{array}{l}\text { cba_political } \\
\text { (std. error) } \\
{[p-\text { value }]}\end{array}$ & Central Bank Political Independence & $\begin{array}{l}2.5514^{*} \\
(1.3181) \\
{[0.0602]}\end{array}$ & $\begin{array}{c}-4.5640^{* * *} \\
(1.2033) \\
{[0.0005]}\end{array}$ \\
\hline $\begin{array}{l}\text { cba_economic } \\
\text { (std. error) } \\
{[p-\text { value }]}\end{array}$ & Central Bank Economic Independence & $\begin{array}{l}6.0203^{* * *} \\
(2.1883) \\
{[0.0090]}\end{array}$ & $\begin{array}{c}-5.1187^{* *} \\
(2.1068) \\
{[0.0198]}\end{array}$ \\
\hline $\begin{array}{l}\text { crisis } \\
\text { (std. error) } \\
\text { [p-value] }\end{array}$ & Financial Crisis Experience (0,1 dummy variable) & $\begin{array}{c}-1.5970^{* *} \\
(0.7892) \\
{[0.0499]}\end{array}$ & $\begin{array}{l}2.5948^{* * *} \\
(0.7268) \\
{[0.0010]}\end{array}$ \\
\hline $\begin{array}{c}\text { eca } \\
\text { (std. error) } \\
\text { [p-value] }\end{array}$ & Europe and Central Asia (ECA) region dummy & $\begin{array}{c}0.8257 \\
(0.7786) \\
{[0.2951]}\end{array}$ & $\begin{array}{c}-1.2116 \\
(1.6519) \\
{[0.4677]}\end{array}$ \\
\hline \multirow[t]{7}{*}{$\begin{array}{l}\text { Constant } \\
\text { (std. error) } \\
\text { [p-value }]\end{array}$} & Intercept term & $\begin{array}{l}19.73^{* * *} \\
(6.5251) \\
{[0.0044]}\end{array}$ & $\begin{array}{c}-13.57^{* * *} \\
(4.5010) \\
{[0.0045]}\end{array}$ \\
\hline & Log-Likelihood & -94.02 & -89.84 \\
\hline & Akaike Information Criterion (AIC) & 4.2456 & 4.0751 \\
\hline & Bayesian information criterion (BIC) & 4.6316 & 4.4612 \\
\hline & $\begin{array}{l}\text { R-squared } \\
\left\{\text { Adjusted } R^{2}\right\}\end{array}$ & $\begin{array}{l}0.4674 \\
\{0.3445\}\end{array}$ & $\begin{array}{l}0.5224 \\
\{0.4121\}\end{array}$ \\
\hline & $\underset{[p \text { - stalistic }]}{F}$ & $\begin{array}{l}3.8032^{* * *} \\
{[0.0016]}\end{array}$ & $\begin{array}{l}4.7393^{* * *} \\
{[0.0003]}\end{array}$ \\
\hline & $\begin{array}{l}\text { BP Heteroskedasticity } \\
{[p-\text {-value }]}\end{array}$ & $\begin{array}{l}7.1781 \\
{[0.6186]}\end{array}$ & $\begin{array}{l}11.13 \\
{[0.2668]}\end{array}$ \\
\hline
\end{tabular}

Notes: This table shows the OLS regression estimates of the $\phi^{g d p}$ and $\phi^{d e f}$ parameters from the regressions of $\hat{\beta}^{g d p}$ and $\hat{\beta}^{\text {def }}$ on the union of the selected relevant subset economic, financial and institutional development indicators obtained from the BMA and Lasso procedures. Standard errors (denoted by std. error in parenthesis below estimates) are homoskedastic standard errors. Two sided probability values (denoted by $p$-value) are reported in square brackets below the estimates and the standard errors. Values in the bottom part of the table show standard regression goodness-of-fit and mis-specification indicators. The entry next to BP Heteroskedasticity is the Breusch-Pagan test for heteroskedasticity. The asterisks ***, $* *$, and ${ }^{*}$ denote significance at the $1 \%, 5 \%$, and $10 \%$ levels, respectively.

(1) denotes values that have been log transformed. 
The coefficient estimates are overall consistent with those reported in Table 5, with some of the standard errors now increased due to the extra inclusion of insignificant or unimportant variables, thereby affecting the precision and significance of the estimates. Comparing standard model selection criteria such as the Akaike Information Criterion (AIC) and the Bayesian Information Criterion (BIC) to evaluate model fit, it is clear that the better fitting model, conditional on the number of parameters that are included, is the one that is selected from the BMA and Lasso procedures reported in Table 5. 